\title{
Morphological and Functional Types of Neurons in Cat Ventral Posterior Thalamic Nucleus ${ }^{1}$
}

\author{
C. -T. YEN, ${ }^{2}$ M. CONLEY, ${ }^{3}$ AND E. G. JONES ${ }^{4}$ \\ James L. O'Leary Division of Experimental Neurology and Neurological Surgery and McDonnell Center for Studies of Higher Brain \\ Function, Washington University School of Medicine, Saint Louis, Missouri 63110
}

\begin{abstract}
Neurons in the thalamic ventral posterior (VB) nucleus of the cat were investigated by extracellular and intracellular recording and by anatomical methods involving either the retrograde transport of horseradish peroxidase (HRP) or the intracellular injection of HRP. Two morphological types of neurons could be detected by retrograde labeling from small injections of HRP in the internal capsule adjacent to VB. These two and one other type, judged to be an interneuron, could also be identified by intracellular staining. Type I cells are large, have thick proximal dendrites which branch in a tuft-like manner, and thick, rapidly conducting axons. They possess few or no dendritic appendages. Type II cells are smaller and have slender proximal dendrites which branch dichotomously and thin, slower conducting axons. Those injected intracellularly are covered in fine, hair-like dendritic appendages.
\end{abstract}

Type III cells are small and have thin processes that give rise to many bulbous dilatations and no obvious axon. Type I and type II cells give off slender axon collaterals in the thalamic reticular nucleus but not in VB. Examples of both types of cell could be antidromically activated from the somatic sensory cortex. Type I and type II cells recovered histologically after intracellular recording included examples of most types of receptive field, including several forms of cutaneous and deep fields, as classified by us in a parallel intra- and extracellular study of unit responses. All but one type I cell, however, responded in a transient manner to peripheral stimulation. The remaining type $I$ cell and all members of an admittedly small sample of type II cells responded in a sustained manner. The sample of recovered interneurons and of units that could not be driven antidromically from the cerebral cortex suggested that they, too, included all receptive field types.

We conclude that submodality specificity in VB is not represented by morphological specificity in thalamocortical

Received August 7, 1984; Revised October 8, 1984;

Accpeted November 28, 1984

1 This work was supported by Grants NS10526, NS22317, and T32NS507072 from the National Institutes of Health, United States Public Health Service, and by Washington University McDonnell Center. We thank Ms. Bertha McClure for technical assistance.

2 Present address: Department of Zoology, National Taiwan University, Taipei, Taiwan, R.O.C.

${ }^{3}$ Present address: Department of Anatomy, Vanderbilt University, Nashville, TN 37232.

${ }^{4}$ To whom correspondence should be sent, at his present address Department of Anatomy, California College of Medicine, Irvine, CA 92717. relay cells or interneurons. Some other functional parameter, such as tonic or phasic responsiveness, may be more obviously correlated with relay cell morphology.

The ventrobasal complex ${ }^{5}$ VB) of the monkey thalamus can be divided into a central core to which cutaneous mechanoreceptors project and an anterodorsally situated shell to which deep mechanoreceptors project (Poggio and Mountcastle, 1963; Jones and Friedman, 1982). Anatomical studies show that the core and shell regions project to different areas of the first somatosensory (SI) cortex (Friedman and Jones, 1981; Jones and Friedman, 1982). Electrophysiological studies indicate that within the cutaneous core region there is a finer submodal organization. In the squirrel monkey, Dykes et al. (1981), recording multiunit responses, found that within VPL, separate zones of slowly adapting (SA), rapidly adapting (RA), and Pacinian units were encountered, and Jones et al. (1982) showed that neurons in rostrocaudal elongated rods within the cutaneous core represented single submodalities.

In VB of the cat, there is some evidence for a similar pattern of organization (Andersen et al., 1966; Fisher et al., 1983) and, in addition, high threshold (nociceptive) units have been described along the lateral and ventral fringe of VPL (Honda et al., 1983; Kniffki et al., 1983).

Morphological studies of VB in the cat suggest that it contains three types of neuron, two types of projection neurons, one resembling type I and another resembling type $V$ neurons as these terms have been used for cells in the dorsal lateral geniculate nucleus (Guillery, 1966; Updyke, 1979), and a class of interneurons (Tömböl, 1967; Rainey and Jones, 1983; Spreafico et al., 1983) which appear to be identical to cells that stain immunocytochemically for glutamic acid decarboxylase, the rate-limiting enzyme in the synthesis of GABA (Penny et al., 1983; Spreafico et al., 1983). In the Galago VB, a similar classification of projection neurons and interneurons has been made (Pearson and Haines, 1980).

The physiological evidence for submodal-specific groups of cells within VB raises the question of whether specific morphological cell types can be localized within them. In the present study we have examined the relationship between cell morphology and physiology in cat VB using anatomical and physiological approaches, including the direct approach of intracellular recording and injection. The results suggest that the conventionally defined physiological submodalities (cutaneous, deep, Pacinian, etc.) cannot be correlated with independent morphological cell classes. Instead, VB appears to be composed of two types of projection neuron, each of which encompasses all submodalities, and a single class of local circuit or

\footnotetext{
${ }^{5}$ The ventrobasal complex consists of the ventral posterior lateral (VPL) and ventral posterior medial (VPM) nuclei, minus the basal ventral medial $(\mathrm{VMb})$ or taste relay nucleus
} 


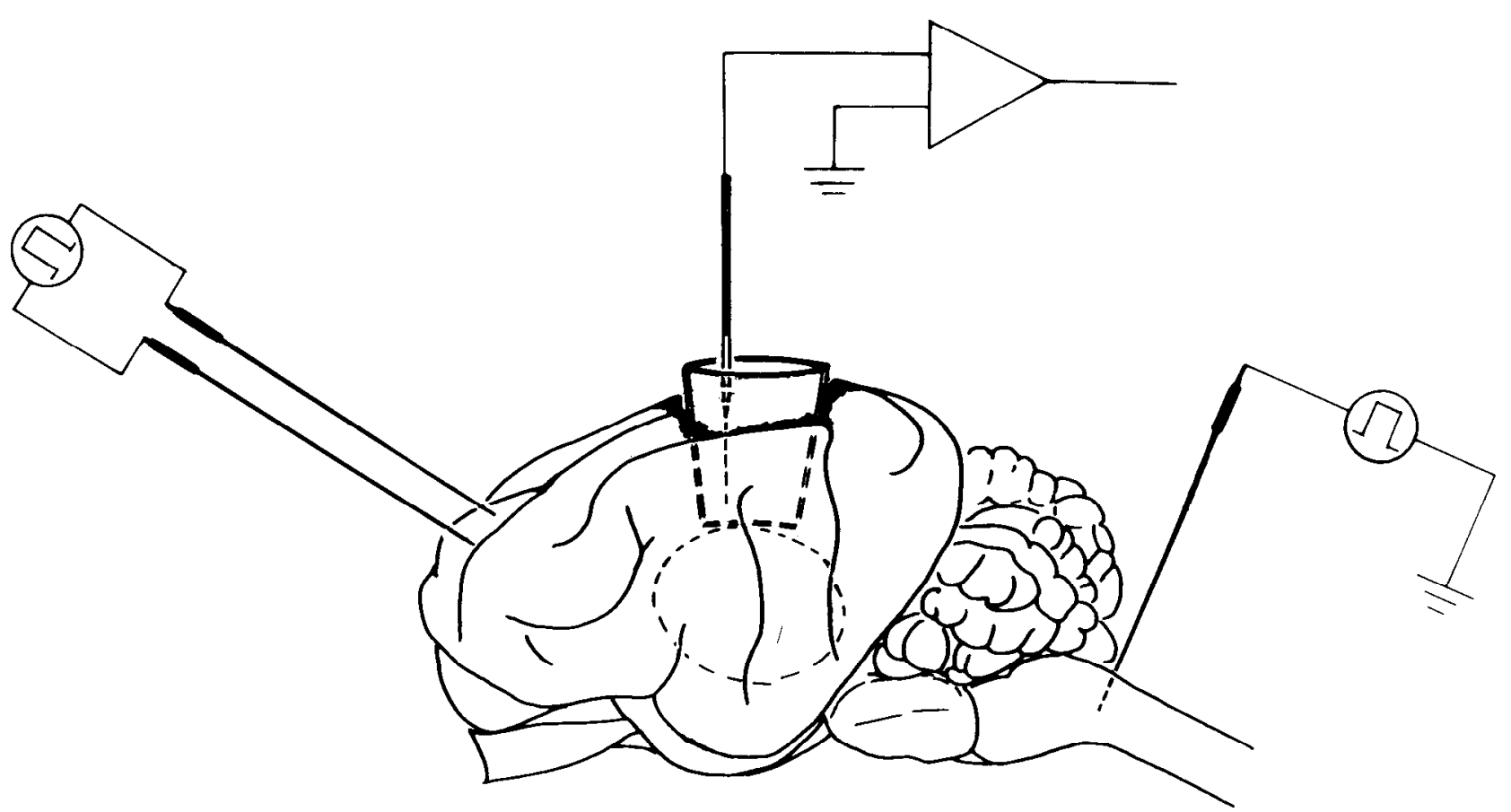

Figure 1. Schematic drawing of the intracellular recording preparation, with a plastic cylinder providing unobstructed access to the thalamus. Stimulating electrodes are shown in the cortex and medial lemniscus. Other stimulating electrodes were placed on peripheral nerves.

interneuron. A preliminary report has appeared (Yen and Jones, 1983).

\section{Materials and Methods}

Animal preparation. Three sets of experiments were carried out in order to assess VB cell morphology and its relation to modality specificity. The first set involved the retrograde labeling of VB neurons from injections of horseradish peroxidase (HRP) placed in the internal capsule. The second set was an intra- and extracellular study of the physiological types of neurons in VB. The third set involved the intracellular injection of HRP into physiologically characterized VB cells.

Extracellular HRP injections. In order to obtain a large sample of VB projection neurons for morphological analysis, in 6 cats anesthetized with Nembutal, iontophoretic injections of HRP $(20 \%$ solution, Sigma type $\mathrm{VI}$ ) were made in the internal capsule just rostral and lateral to VB. Micropipettes drawn on a Kopf vertical electrode puller were filled with 5 to $10 \%$ HRP (Worthington) in a $0.1 \mathrm{M}$ Tris-buffered $0.5 \mathrm{M} \mathrm{KCl}$ solution ( $\mathrm{pH} 7.3$ to 7.4 ). The exact placement of the filled HRP electrodes was guided by multiunit mappings across the rostral pole of VB. The injections were made posterior to the frontal level of the recording tracks, over a period of $30 \mathrm{~min}$, by passing 1 to 3 $\mu \mathrm{A}$ anodal current ( $1 \mathrm{sec}$ on, $1 \mathrm{sec}$ off). Animals survived for 24 to $48 \mathrm{hr}$, after which they were perfused with a mixture of $1 \%$ paraformaldehyde and $2.5 \%$ glutaraldehyde in $0.1 \mathrm{M}$ phosphate buffer. Thereafter, the brains were soaked in 30\% phosphate-buffered sucrose, sectioned sagittally at $50 \mu \mathrm{m}$ on a freezing microtome or vibratome, and processed for peroxidase histochemistry using the cobalt-enhanced diaminobenzidine method of Adams (1977). Most sections were counterstained with thionin.

Physiological recording. Fifty-two cats $(1.9$ to $5.8 \mathrm{~kg})$ were used in this part of the study. Animals were anesthetized initially with sodium pentobarbital ( $35 \mathrm{mg} / \mathrm{kg}$ i.p.). A cannula was then placed in the femoral vein for the administration of supplemental anesthetic (5 $\mathrm{mg} / \mathrm{ml}$ ), muscle relaxant (Gallamine triethiodide), and fluids; a second cannula was placed in the femoral artery to monitor arterial blood pressure. A level of anesthesia was maintained such that arterial blood pressure was kept at approximately $120 \mathrm{~mm} \mathrm{Hg}$, and the animal's pupils remained constricted. Animals were respired artifi- cially with a positive pressure respirator, and end-tidal $\mathrm{CO}_{2}$ concentration was monitored continuously and maintained between 3.5 to $4.5 \%$. A warm water blanket and infrared lamp were used to maintain body temperature at approximately $37.5^{\circ} \mathrm{C}$. Just before intracellular recordings began, a bilatcral pneumothorax was performed in order to minimize movements associated with respiration.

Before an animal was placed into the stereotaxic frame, silastic cuffs containing bipolar silver wire electrodes were placed bilaterally on the intact median and sciatic nerves. The nerve cuffs were placed on the median nerves just below the axilla and on the sciatic nerves in the popliteal fossa.

Once in the stereotaxic frame, the skull was opened over the first somatic sensory cortex (SI) and in the region overlying the thalamus on the same side. After a brief, multiunit mapping of the SI cortex, a bipolar, silver ball stimulating electrode was placed on the surface of $\mathrm{SI}$ in the region of the forelimb representation or multiple electrodes ( 8 to 15) were placed over the greater part of the body representation. The electrodes were secured in place with a layer of soft paraffin (paraffin oil/low melting point paraffin, 1:1 V/V).

The cortex and hippocampus overlying the thalamus were removed by gentle aspiration, the walls of the cavity being lined carefully with oxidized surgical cellulose. A plastic cylinder $(1 \mathrm{~cm}$ in diameter) was placed in the cavity so as to maintain direct access to the dorsal surface of the thalamus, and all electrode penetrations into the thalamus were made through it (Fig. 1)

In addition to the stimulating electrodes placed on peripheral nerves and the SI cortex, a varnish-insulated monopolar, tungsten electrode (resistance, $\sim 100$ kilohms) was inserted in the ipsilateral medial lemniscus close to its decussation. Placement of the lemniscal electrode was guided by recording multiunit evoked responses to electrical stimulation of the median and sciatic nerves. A bipolar, "cutaneous" electrode made from a pair of 27 gauge needles and which could be inserted into the skin directly was used to evaluate peripheral receptive field orthodromic latencies. Activation and temporal parameters for all stimulating electrodes were controlled by a Digitimer and $\mathrm{DS}_{2}$ stimulus isolation units.

Recordings. Glass microelectrodes with internal microfilaments were pulled from either a Brown-Flaming type electrode puller (Sutter $\mathrm{P}-77$ ) or a vertical electrode puller (Kopf 700C) and were filled with 
Figure 2. Identification of a thalamocortical neuron in extracellular records. $A$, Single shock slimulation of the ipsilateral SI cortex (CT) or of medial lemniscus $(M L)$ leads to antidromic and orthodromic spikes at constant latency (seven superimposed traces). $B$, Each pair of records shows a high gain $A C$ above and a low gain DC record below. On the left, stimulation of SI cortex with a 3-V, 20- $\mu \mathrm{sec}$ shock at one per sec shows a constant latency antidromic spike response (four superimposed traces). On the right, the same stimulus applied to the ipsilateral SI cortex at a rate of 100 per record shows a fixed latency in the early antidromic response of the axon initial segment and with occasional failure of the ensuing soma-dendritic response (ten superimposed traces). C, A typical collision test. In traces 1 and 2, stimulation of the ipsilateral SI cortex resulted in a fixed latency antidromic spike (open arrow). In trace 3 , collision with a spontaneously occurring spike (solid arrow) falling within the critical period blocked the antidromic response. In trace 4 , a spontaneous spike falling outside the critical period did not block the antidromic response.
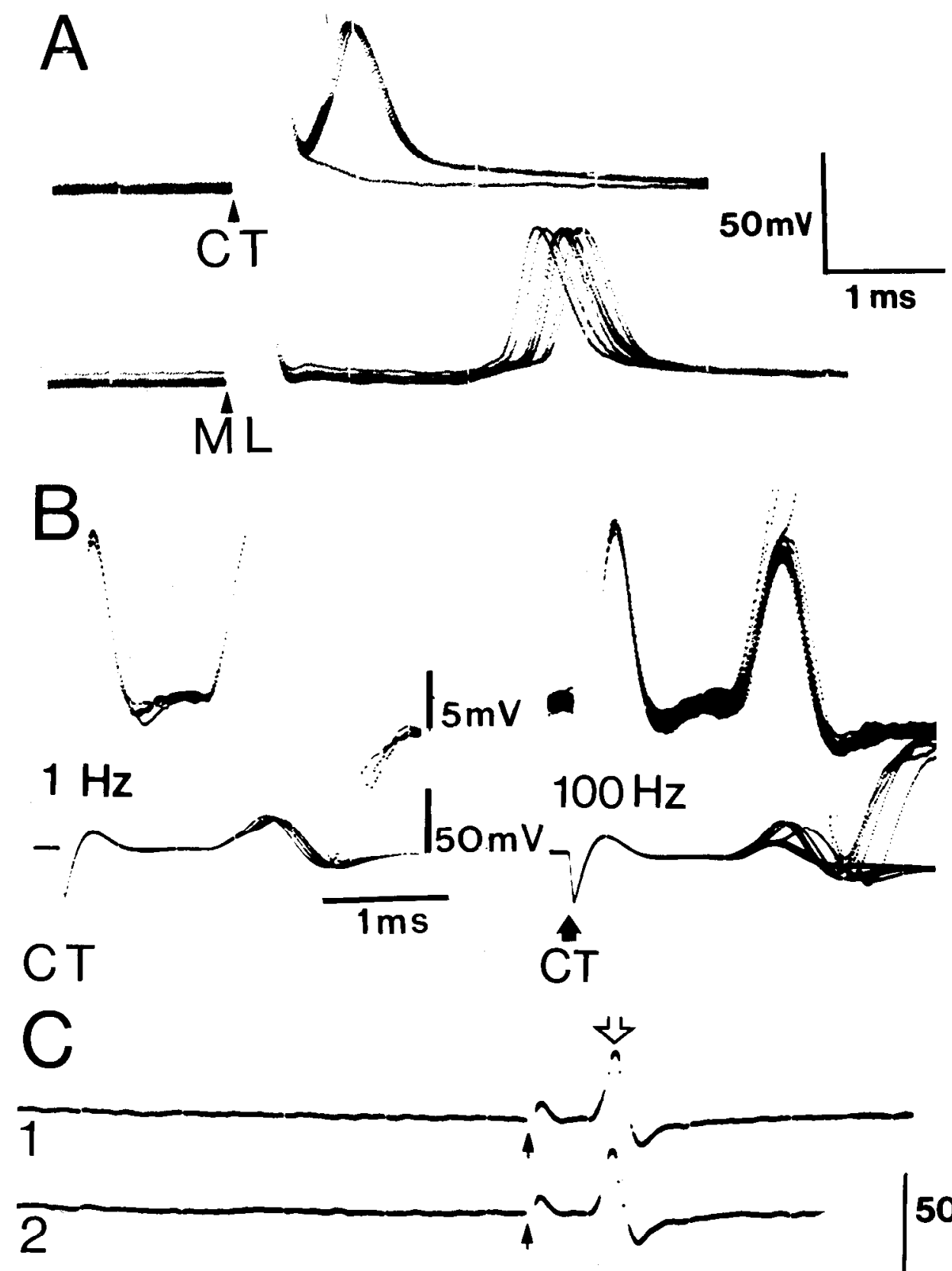

$50 \mathrm{mV}$
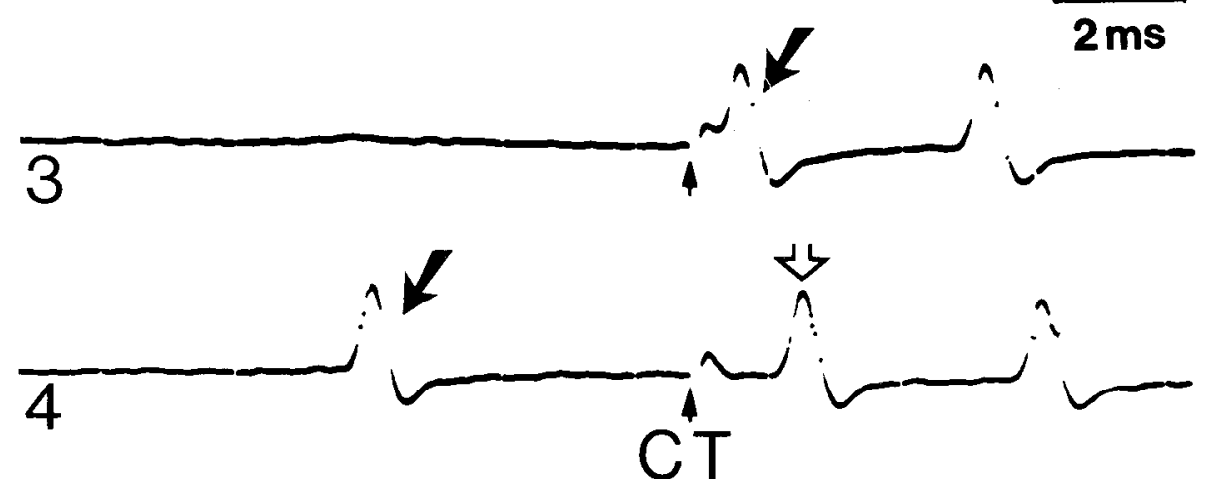

HRP (5 to $10 \%$; Worthington) in a $0.1 \mathrm{M}$ Tris buffer, $0.5 \mathrm{M} \mathrm{KCl}$ solution $(\mathrm{pH}=7.3$ to 7.4$)$. The DC resistances of the electrodes were within the range of 40 to 200 megohms. Recording microelectrodes were lowered into the thalamus using a remote-controlled hydraulic microdrive (D. Kopf). Signals were led through a head stage to a high-voltage electrometer (Eutectics 400) and monitored on storage oscilloscopes (Tektronix 5113) and via an audio amplifier and loudspcaker. Permanent records were taken directly from the oscilloscope face with a Polaroid camera.

Recordings were judged as axonal or somatic based on established criteria: recordings that were monophasic with a rapid rising phase and short spike duration (less than $1 \mathrm{msec}$ ) were called 

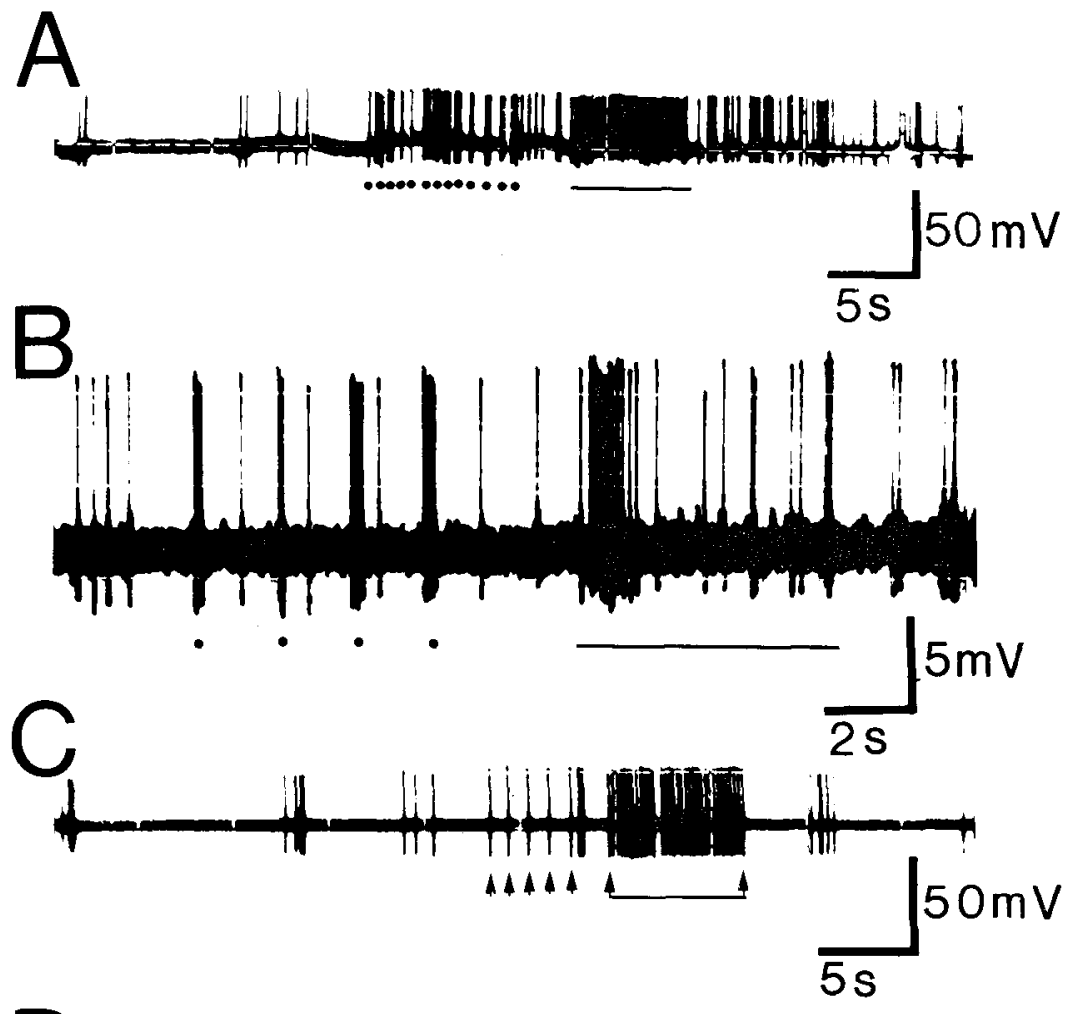

Figure 3. Examples of the responses of VB neurons recorded extracellularly and in relation to some of the different types of stimuli used in the study. A, Hair-sustained $(\mathrm{Hs})$ unit, with a receptive fieid on the dorsum of the contralateral wrist. Dots indicate individual stimuli consisting of puffs of air; the line indicates continual stimulation by a camel hair brush. $B$, Hair-transient $(\mathrm{Ht})$ unit, with a receptive field on the lateral aspect of the fifth digit of the contralateral forepaw; stimuli are the same as in $A$. C, Tap 1 unit responding to repetitive light tapping over the contralateral triceps brachii muscle. Individual stimulus arrows indicate low-frequency tapping, and arrows linked by a line indicate high frequency tapping. $D$. Joint unit inhibited during extension $(e)$ and excited during flexion $(f)$ of the contralateral wrist joint. $E$. High threshold $(\mathrm{HT})$ unit responding at higher frequency to each of three increments of noxious stimulation applied by squeezing skin over triceps brachii tendon between toothed forceps. The thickness of the line indicates low-, medium-, and high-intensity stimulation.

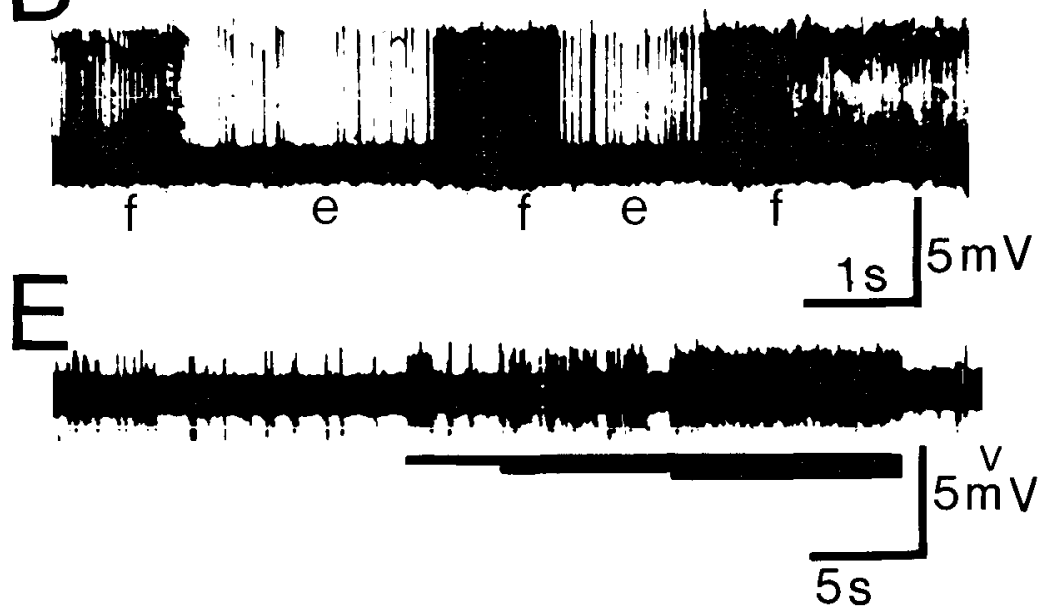

All HRP Labeled Cells

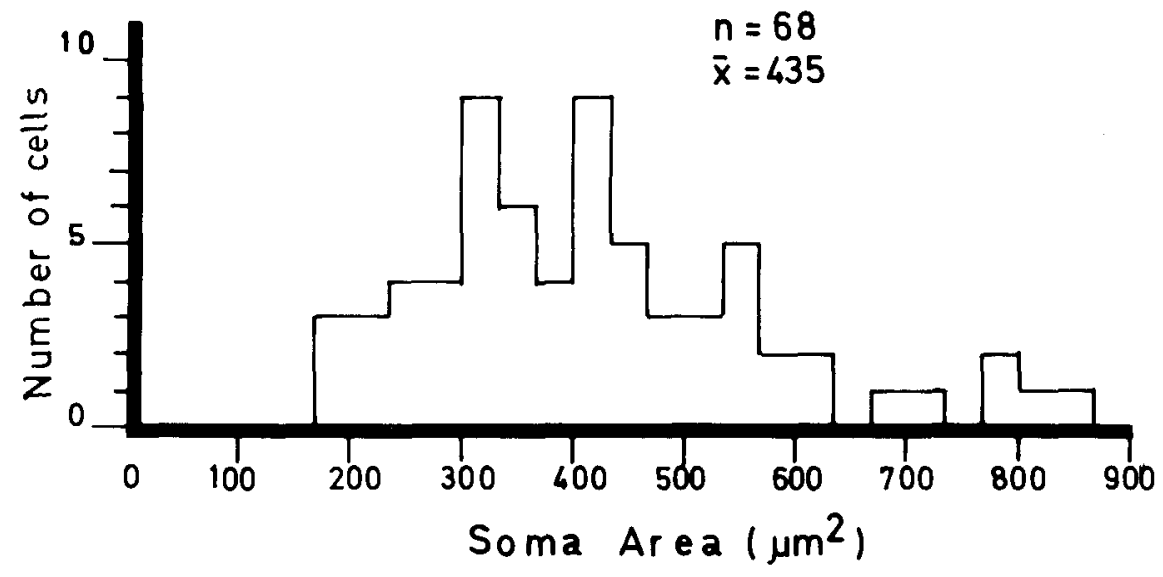

Figure 4. Size distribution of all HRP-labeled cells following an injection into the internal capsule adjacent to VB. Soma areas range from 165 to $860 \mu \mathrm{m}^{2}$ and are distributed normally about a mean of $435 \mu \mathrm{m}^{2}$. 

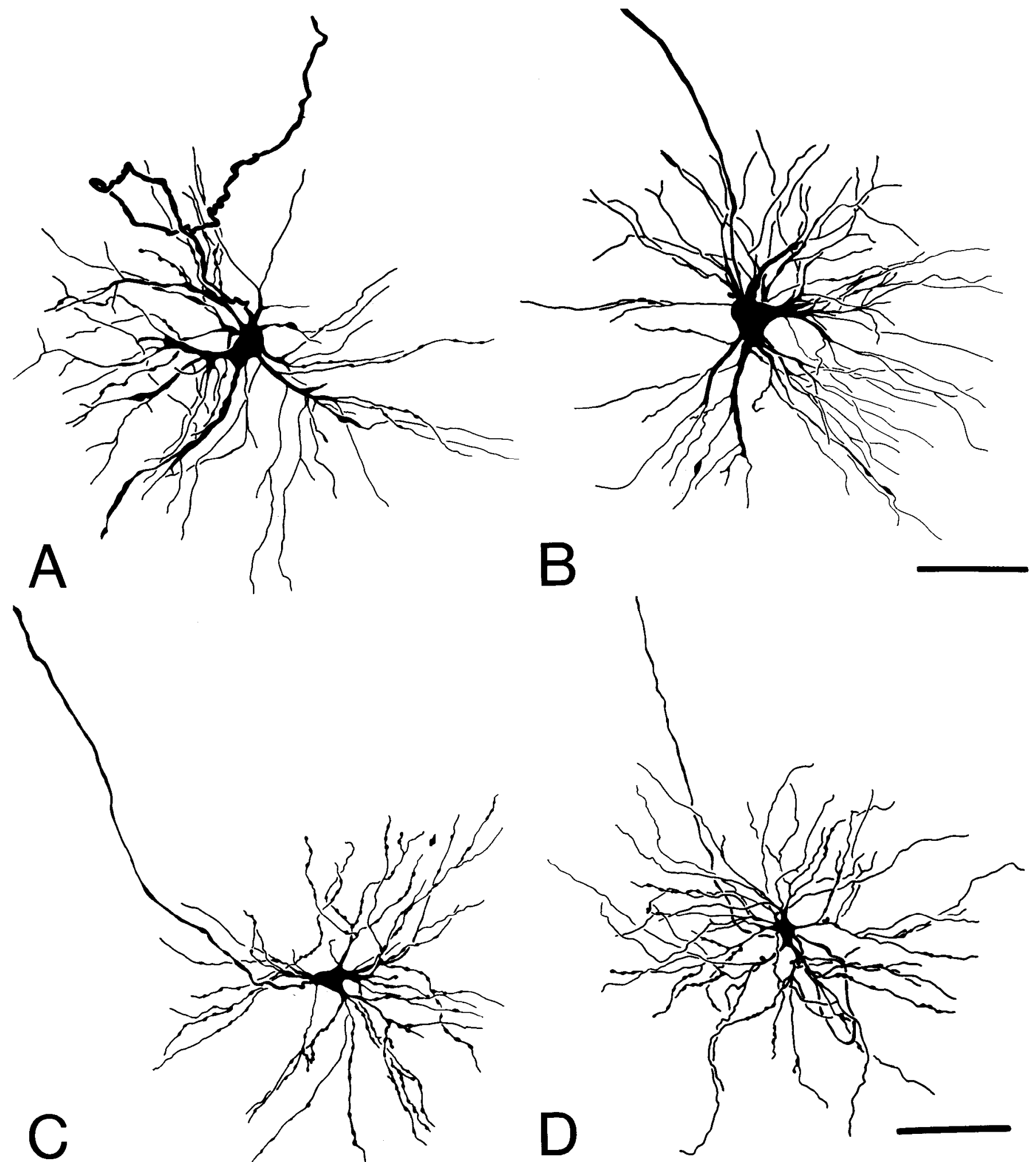

Figure 5. $A$ and $B$, Camera lucida drawings of retrogradely labeled type 1 cells. Note large soma, tufted branching of primary dendrites, and thick axons $B a r, 100 \mu \mathrm{m} . C$ and $D$, Camera lucida drawings of retrogradely labeled type II cells. In comparison with $A$, type II cells have smaller somata, thinner, dichotomously branching dendrites, and a thinner axon. Bar, $100 \mu \mathrm{m}$.

axonal; recordings judged as somatic were either intracellular (membrane potential of at least $-40 \mathrm{mV}$ and spike height larger than 30 $\mathrm{mV}$ ) with spontaneous excitatory or inhibitory postsynaptic potentials (EPSP or IPSP) or extraccllular with biphasic shape, longer spike duration ( 1 to $2 \mathrm{msec}$ ) and an inflection point on the rising phase of the spike indicating the initial segment-soma-dendrite (IS-SD) com- ponents. A thalamic neuron was identified as a projection neuron (or thalamocortical, TC neuron) if the recording was somatic and, if the neuron was activated antidromically, from stimulation of SI cortex. Similarly, a fiber was identified as a thalamocortical fiber (TC fiber) if the recording was axonal and the fiber was activated antidromically from stimulation of SI cortex. Three criteria were used to distinguish 

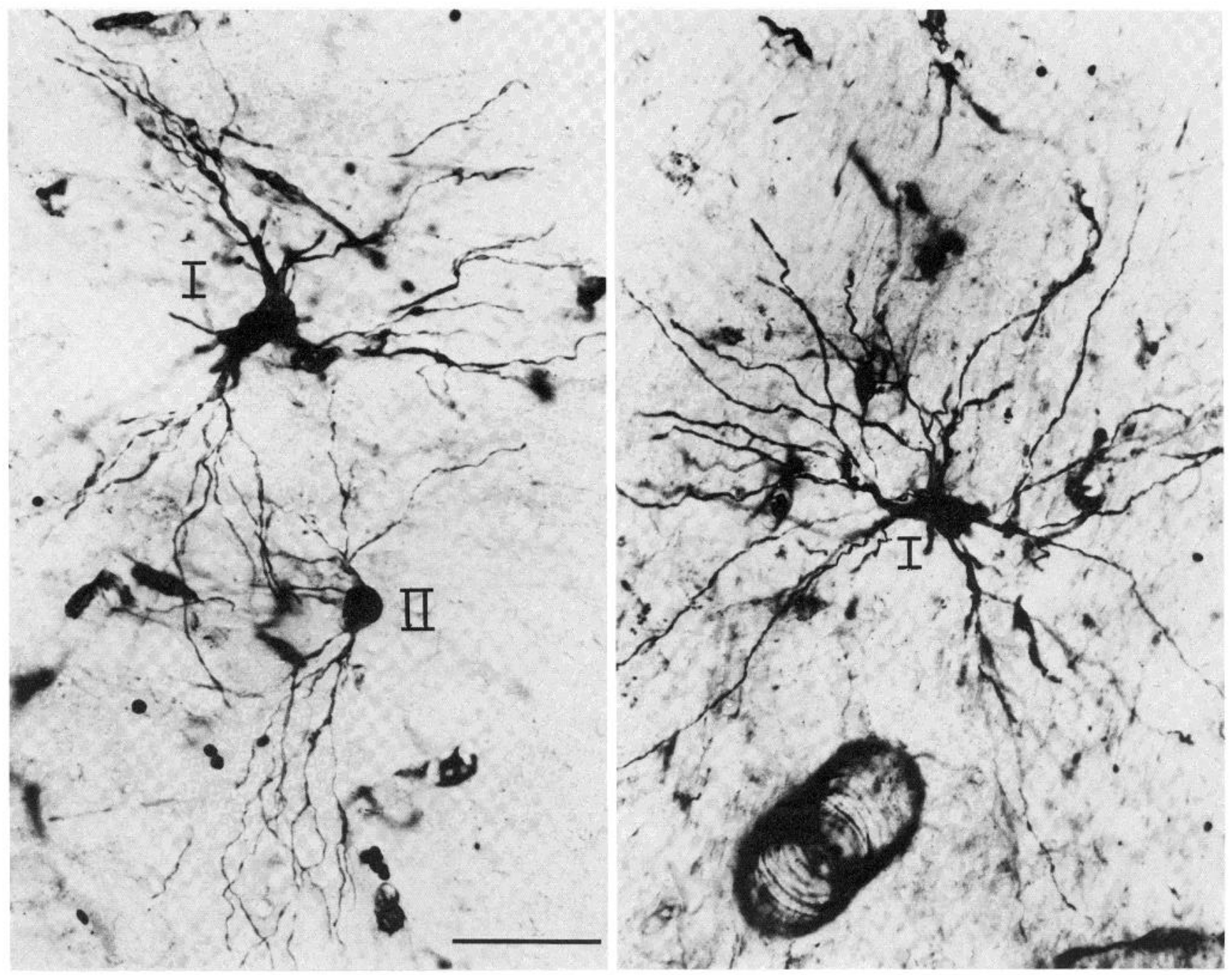

Figure 6. Photomicrographs of retrogradely labeled cells identified as type I or type II. Bar, $50 \mu \mathrm{m}$.

an antidromic spike (Fig. 2): (1) constant latency at a wide range of stimulus strengths; (2) either the whole spike (TC fiber and some TC neurons) or the IS segment of the spike (some TC neurons), followed with fixed latency and $100-\mathrm{Hz}$ stimulation of SI cortex; and (3) the collision test (Bishop et al., 1962; Darian-Smith et al., 1963; Wolstencroft, 1964). Thalamic units which could not be driven antidromically from SI cortex were called "nonantidromic."

No attempt was made to find reversal potentials or to measure conductance changes from evoked depolarizations or hyperpolarizations. An evoked depolarization was called an EPSP if orthodromic spikes were seen to rise from the depolarization and if the depolarization was attenuated significantly when the tip of the electrode moved from an intracellular to an extracellular position. An evoked hyperpolarization was called an IPSP if it was observed intracellularly but not extracellularly.

Terminology and submodal classifications. A variety of stimuli were employed to assess the qualitative (submodal) aspects of VB unit responses. Excitatory receptive fields were explored with an air jet, von Frey hair, wooden applicator, variable tuning fork, and other "natural" stimuli. Joints and muscle bellies were manipulated manually. Qualitative differences were categorized according to the following scheme.

(1) Hair sustained (Hs) - the unit responded to light air puffs and responded continuously to steady, light pressure. (2) Hair transient $(\mathrm{Ht})$ - the unit responded to light air puffs and responded transiently to steady, light pressure. (3) Pressure sustained (Ps) - the unit did not respond to light air puffs, but it responded to weak force (less than $2 \mathrm{gm}$ ) applied to its receptive field and responded continuously to steady, light pressure. (4) Pressure transient (Pt)-same as Ps, except that the response to steady, light pressure was transient. (5) Brush $(B)$ - the unit did not respond to either air jet or light pressure stimuli but did respond to discrete, lightly stroked stimuli moved across its receptive field. (6) Joint $(\mathrm{J})$ - the unit responded to the movement of a joint, usually excited by movement in one direction (flexion or extension) and inhibited by movement in the opposite direction. (7) Tap 1 (T1) - the unit responded most clearly to rapid, light tapping. When tested with a tuning fork, unit responses were time-locked to the vibration frequency. (8) Tap 2 (T2) - the unit did not respond to any of the above-mentioned stimuli, but it did respond to low- and medium-intensity, low-frequency (usually less than $2 \mathrm{~Hz}$ ) tapping. (9) High threshold (HT) - the unit responded to forceful pinching of the skin with forceps or underlying deep structures in the receptive field. The two units found of this type also responded to tapping stimuli, but less vigorously.

Groups 1 to 5 were referred to as "cutaneous;" groups 6 and 7 were referred to as "deep;" and groups 8 and 9 were referred to as "uncertain." Examples of response patterns of $\mathrm{Hs}, \mathrm{Ht}, \mathrm{J}, \mathrm{T} 1$, and $\mathrm{Ht}$ units are shown in Figure 3.

Once a unit was isolated extracellularly, the location and size of its peripheral receptive field was mapped, its submodal class was established, and antidromic and orthodromic latencies were measured; an attempt was then made to penetrate the fiber or neuron 
Figure 7. Soma area distributions of retrogradely labeled VB cells classified as type I (upper histogram) or type II (lower histogram) based on differences in dendritic morphology.
Figure 8. Frequency histogram of soma areas of 180 randomly sampled VB neurons stained for Nissl substance with thionin and taken from the from 62 to $890 \mu \mathrm{m}^{2}$ (mean, $355 \mu \mathrm{m}^{2}$ ). Except for the presence of cells smaller than approximately $200 \mu \mathrm{m}^{2}$, this distribution is similar to that of retro gradely labeled cells in Figure 4. counterstained sections. The distribution ranges
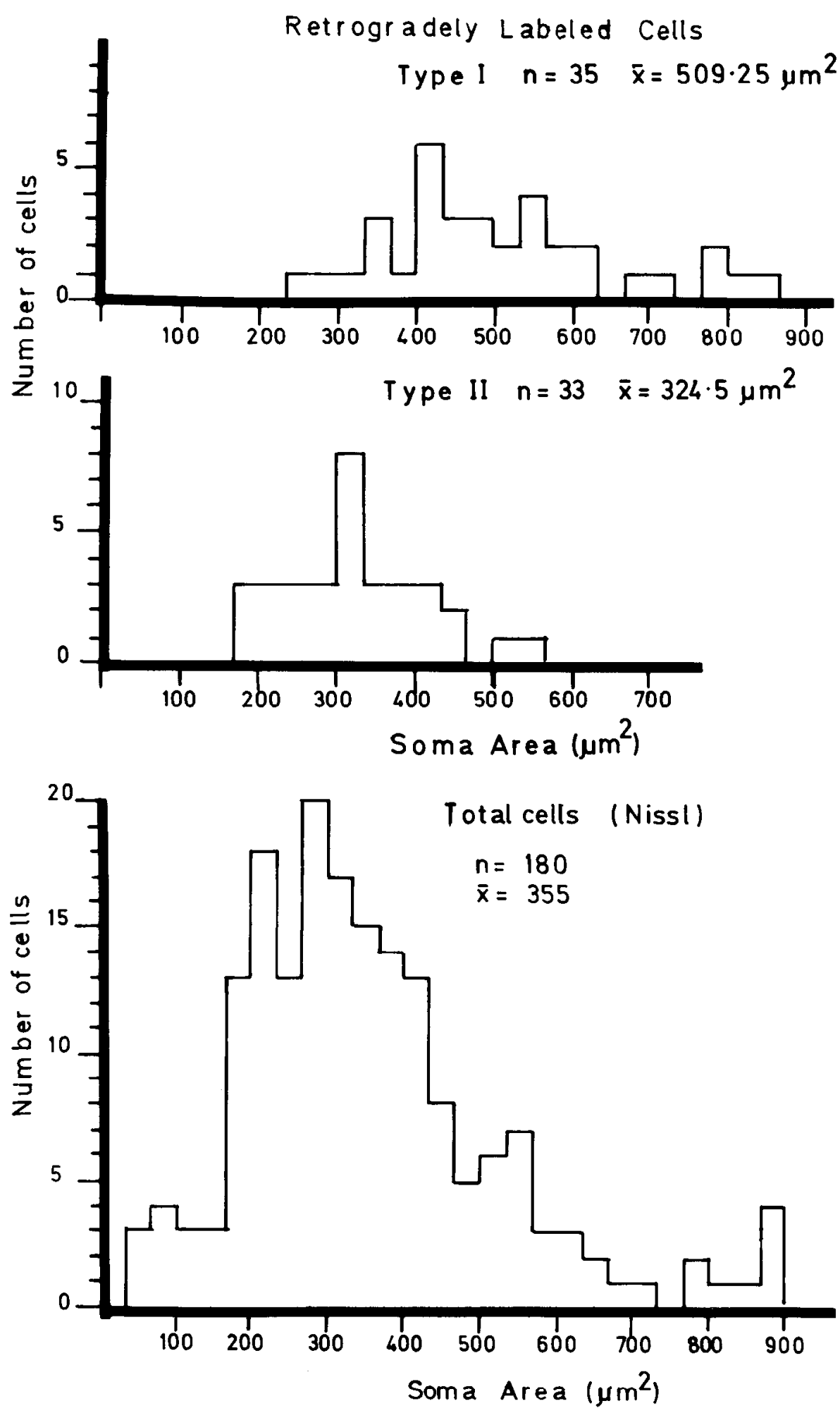

intracellularly. After a successful intracellular penetration, short 100 msec bursts of square wave depolarizing current ( 4 to $20 \mathrm{nA}$ ) (for axons) or $4 \mathrm{nA}$ (for neurons) were passed over a period of 3 to 10 min. Electrode tracks in which HRP injections were made were always separated by at least $1 \mathrm{~mm}$, and multiple injections along a single track were made only rarely in order to facilitate subsequent histological identification of labeled cells and axons.

One hour after the last HRP injection, the animal was perfused through the heart with normal saline, followed by a solution of $1 \%$ paraformaldehyde and $2.5 \%$ glutaraldehyde in $0.1 \mathrm{M}$ phosphate buffer $(\mathrm{pH} 7.4)$. Brains were blocked and allowed to sink in $30 \%$ sucrose buffer at $4^{\circ} \mathrm{C}$. Fifty-micrometer-thick sections were cut either on a freezing microtome or Vibratome and reacted for peroxidase histochemistry using a modification of the cobalt chloride-intensified diaminobenzidine method of Adams (1977). Every fifth section was counterstained with thionin.

Reconstructions. Camera lucida drawings were made of all intracellularly stained neurons and a large sample of neurons labeled retrogradely. Reconstructions of individual neurons were made using camera lucida drawings at progressively, increasing magnification 


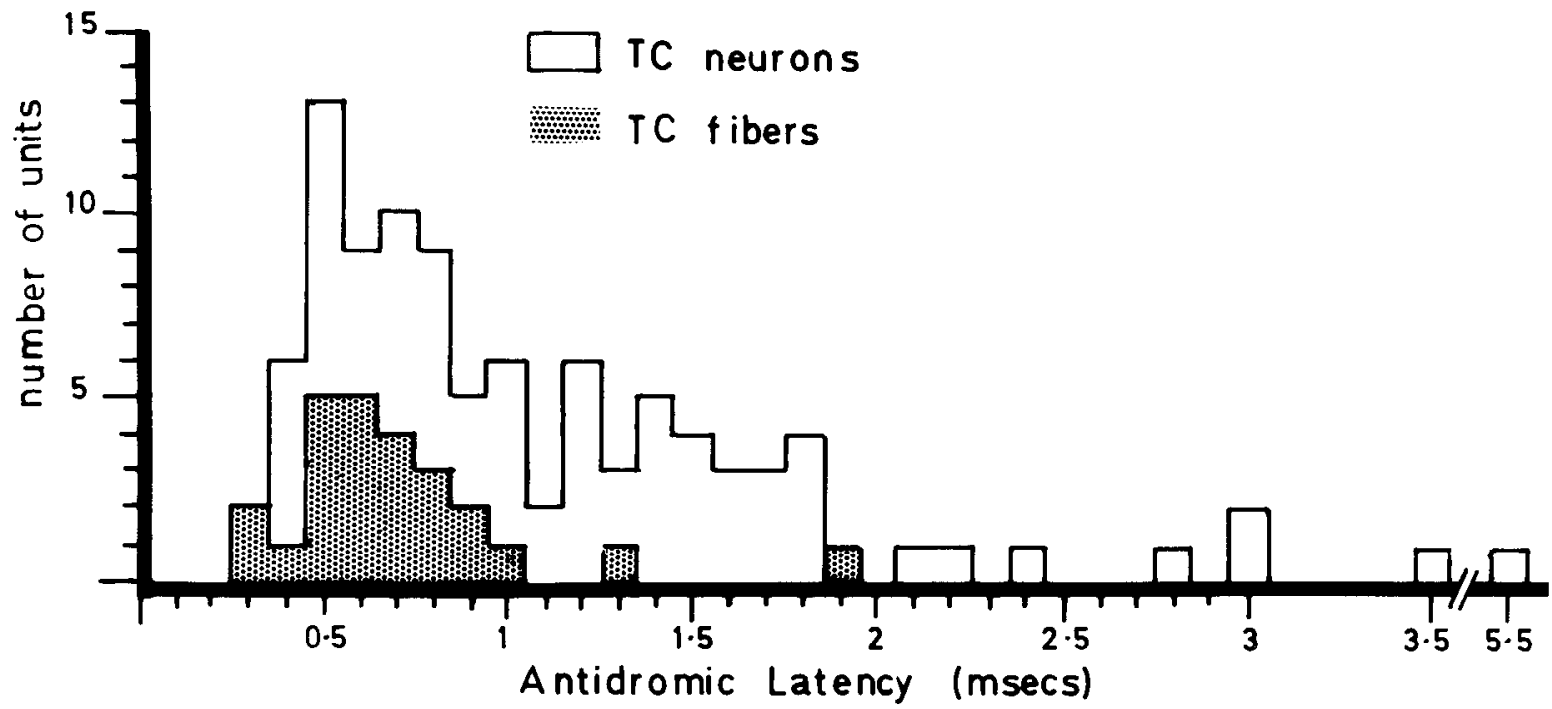

Figure 9. Antidromic latency spectra for TC neurons (solid lines) and TC fibers (stippled bars) in milliseconds. TC neuron latencies range from 0.4 to $5.5 \mathrm{msec}$; TC fiber latencies range from 0.3 to $1.9 \mathrm{msec}$.

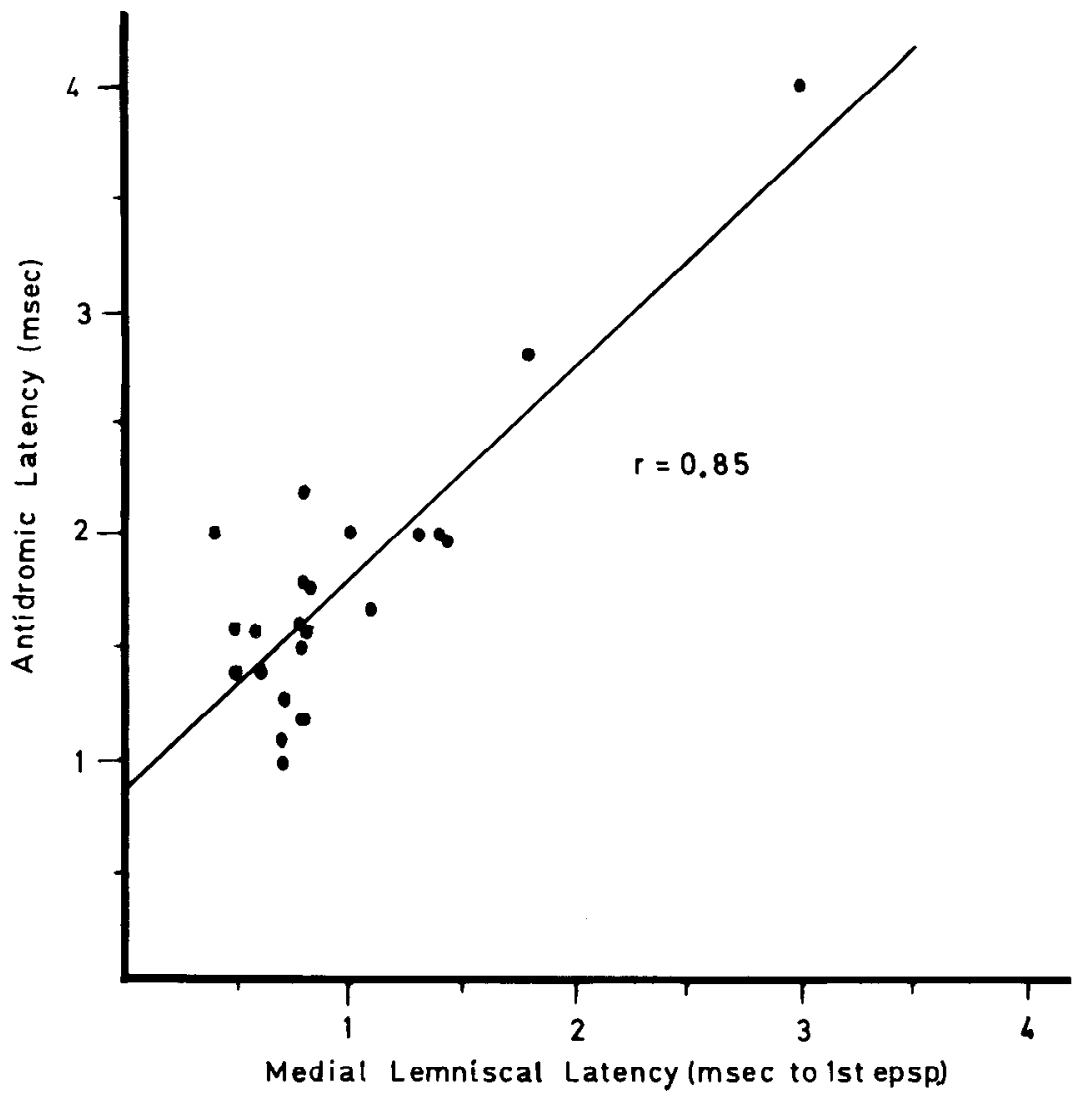

Figure 10. Scatter plot of orthodromic (lemniscal) and antidromic (cortical) latencies for 22 VB units. The two measures are highly correlated; $r=0.85 ; p<0.001$.

$(2.5 \times$ to $1250 \times)$. Where only a single cell was injected or where injected cells were separated by 1 to $2 \mathrm{~mm}$, the identification of portions of cells and axons from section to section presented no problems. Cells labeled retrogradely were only selected for reconstruction if labeled processes could be identified readily in successive sections. Blood vessels, other labeled processes, and nuclear boundaries were plotted carefully in compiling serial reconstructions. Measurements of soma area were made from the camera lucida drawn outlines of the somata using a Zeiss MOP-3 graphics tablet.

\section{Results}

Since the main goal of the present study was to determine whether different morphological classes of VB neurons can be related to different classes of somesthetic afferents, emphasis was placed on quantitative (anatomical and physiological) measures relating these two data sets. In the first set of experiments, extracellular retrograde filling of VB neurons with HRP provided an initial picture of VB projection neuron morphologies. In the second set of experiments, both intracellular and extracellular recordings provided a second, independent picture of VB neurons. Finally, the experiments in which HRP was injected intracellularly into physiologically characterized VB neurons provided a direct correlation of VB cell morphology and physiology

\section{Extracellular injections of HRP}

As a first step in assessing morphological differences between VB projection neurons, injections of HRP were made in the internal 

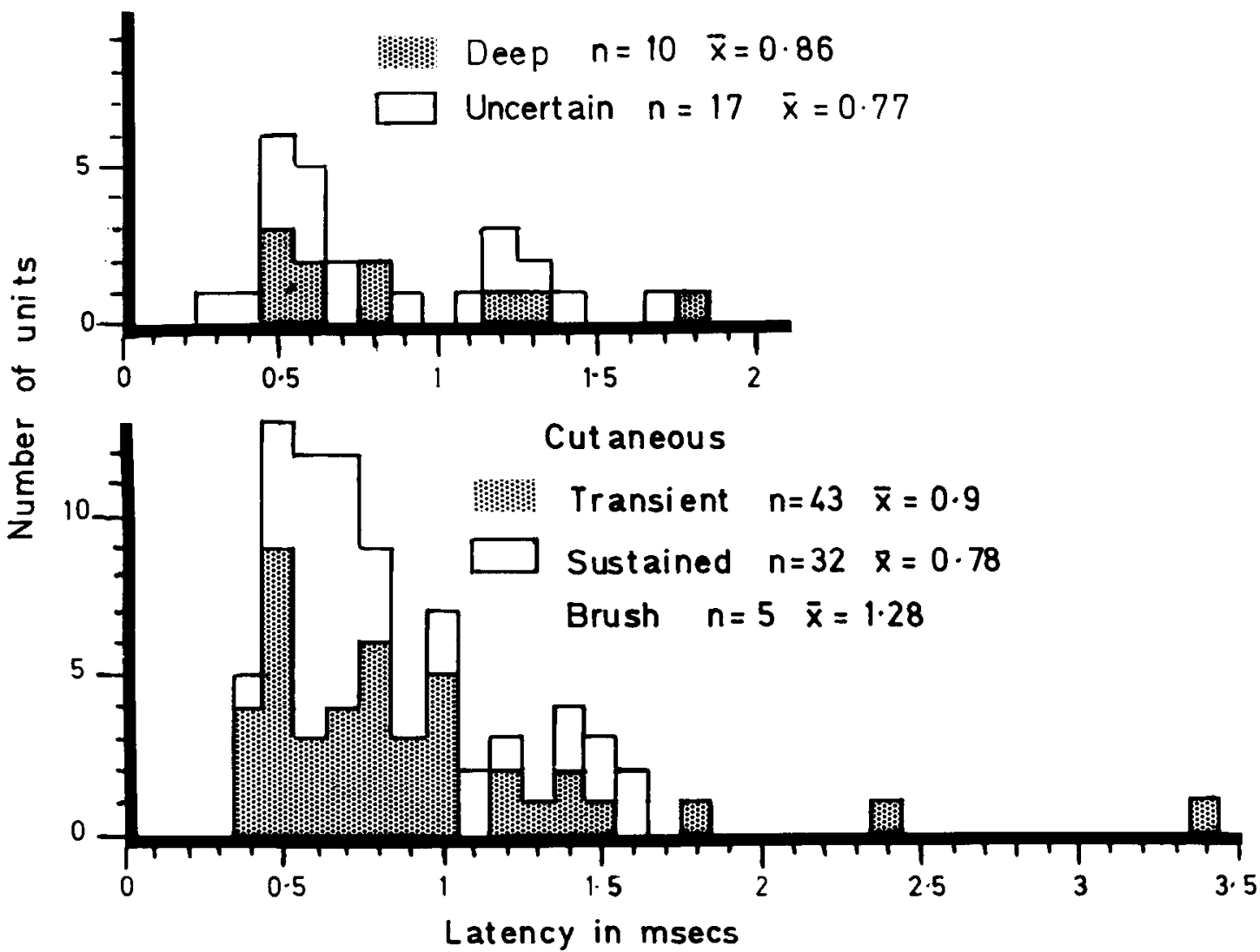

Figure 11. Antidromic latency spectra for VB units classified as "deep" and "uncertain" (upper histogram) compared with those classified as "cutaneous" (lower histogram; only transient and sustained units are plotted). Except for two cutaneous units with transient properties which had latencies longer than $2.0 \mathrm{msec}$, the range and overall shape of the two distributions are quite similar.

capsule just rostral and lateral to VB. These "back filling" experiments produced a large number of retrogradely labeled VB projection neurons sufficient to make an initial categorization of morphological types based on somal, axonal, and dendritic features. Our aim was to obtain a fairly broad picture of the variation in projection neuron morphologies against which the smaller number of intracellularly filled neurons could be compared. Cells selected for analysis were taken from all portions of the VPL nucleus.

When plotted strictly as a function of soma area, the distribution of $V B$ projection neurons does not reveal any obvious delineation into separate groups (Fig. 4). Instead the distribution appears unimodal about a mean of $435 \mu \mathrm{m}^{2}$ (range, 165 to $860 \mu \mathrm{m}^{2}$ ). The overall shape of the distribution, as well as the range of soma areas, is in close agreement with other reports (Penny et al., 1983; Sprealico et al., 1983). In spite of the apparent uniformity in the distribution of projection neuron sizes, when categorized on the basis of dendritic morphology, two distinct groups emerged. The first group, termed type I neurons, is characterized by medium to large somata (mean, $510 \mu \mathrm{m}^{2}$ ) - large, smooth primary dendrites which radiate in all directions from the soma and which give rise to tufts of multiple secondary dendrites, most of which are finer in caliber and which branch once or twice more dichotomously along straight courses (Fig. 5, $A$ and $B$, and Fig. 6). Except for a few spine-like processes on distal dendrites and occasional swellings in sorne processes, the type I neurons do not have dendritic appendages. Type II neurons are characterized by smaller somata (mean, $325 \mu \mathrm{m}^{2}$ ), thinner primary dendrites which branch dichotomously instead of in tufts. Their course is more sinous than those of type I neurons (Fig. 5, C and $D$, and Fig. 6). Some type II neurons have srriall collections of fine, hairlike, or stalked appendages at primary dendritic branch points, but these never number more than 4 to 5 at any particular location or 15 to 20 per neuron. When classified first as type I or type $\|$ and then plotted as a function of soma area (Fig. 7), VB projection neurons form two populations which differ significantly in terms of mean soma area ( $p<0.01$; the Student's $t$ test).

In addition to larger average soma areas, type I neurons tend to have larger dendritic fields than type II neurons (average diameter, $365 \mu \mathrm{m}$ versus $310 \mu \mathrm{m}$ for type II neurons) and larger-caliber axons (average diameter, $1.8 \mu \mathrm{m}$ versus $1.3 \mu \mathrm{m}$ for type $\|$ neurons). The difference in axon diameter was significant $(p<0.001$; the Student's $t$ test).

These two groups of cells do not constitute all of the cells within $V B$, as can be seen from mesurements of soma area in normal Nissl-stained material from the same animals (Fig. 8). It is apparent from the distribution shown in Figure 8 that most of the cells which remain unlabeled following injections of HRP in the internal capsule adjacent to VB are small neurons with somal areas in the range of 70 to $200 \mu \mathrm{m}^{2}$. Recent evidence suggests that this same group of cells is not labeled when HRP is injected into Si cortex, lending support to the idea that they are interneurons (Penny et al., 1983; Spreafico et al., 1983). In general, type I cells were found throughout the nuclous, as were type II cells and small cells, though the type II cells were somewhat more numerous in the ventral portion of VB.

\section{Single unit analysis of $\mathrm{VB}$}

For intracellular recording and injection experiments, first VB units were characterized extracellularly according to receptive field size, location, orthodromic (input), and antidromic (from the cortex) conduction latencies and submodality; then an attempt was made to impale the neuron or axon. Since not all cells that were isolated and characterized extracellularly were penetrated intracellularly and since not all cells that were penetrated intracellularly were recovered histologically, we analyzed the single unit data for evidence of physiological groups independently of the intracellular staining. Our rationale, again, was to use this larger body of physiological data to obtain an initial picture of the physiological features which charac- 


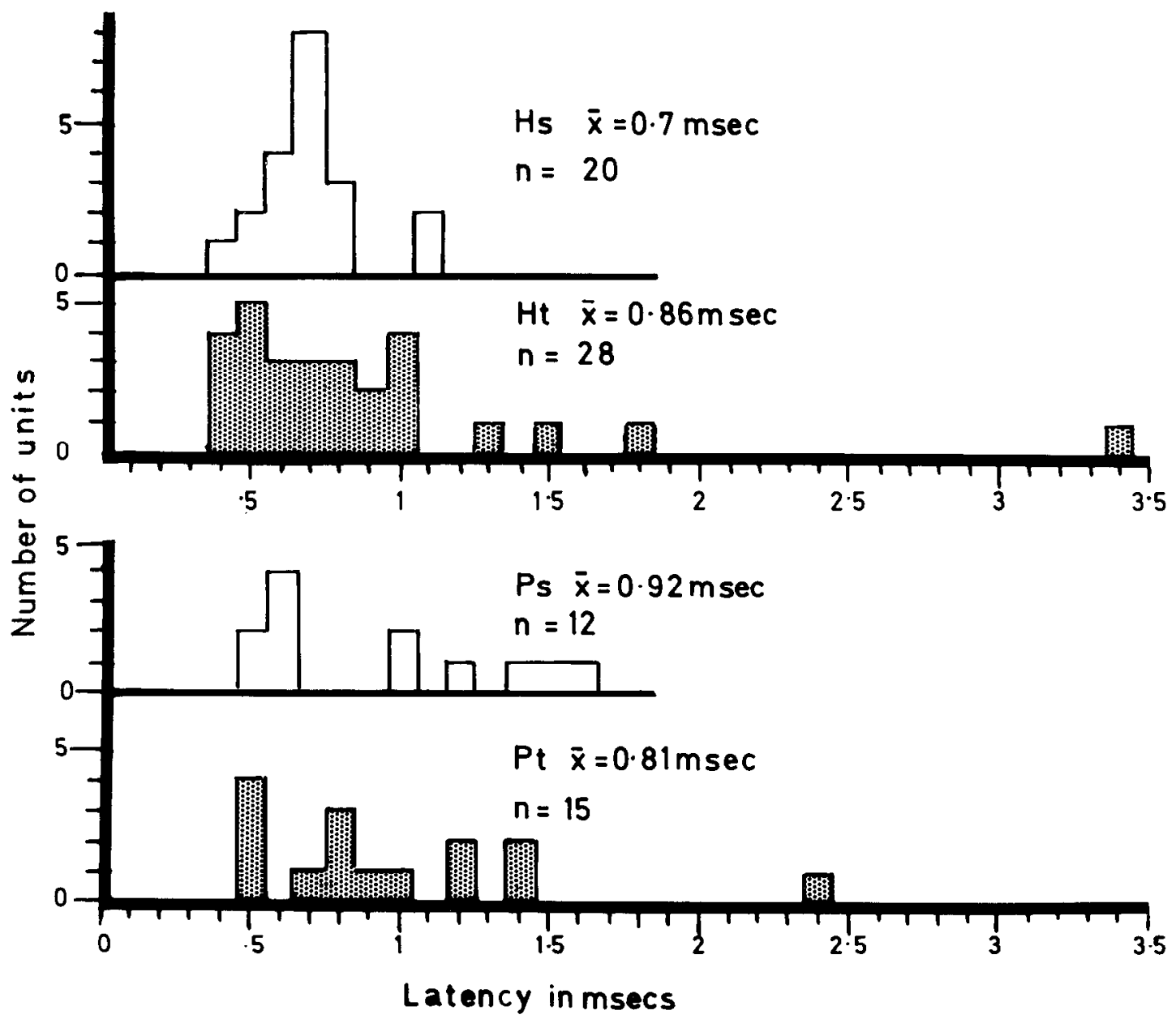

Figure 12. Upper histograms, Antidromic latency spectra (from cortex) for cells identified as hair-sustained (solid lines) and hair-transient (stippled). Lower histograms, Antidromic latency spectra (from cortex) for cells identified as pressure-sustained (solid lines) and pressure-transient (stippled). All groups have similar latency spectra.

terize VB cells and axons and against which units characterized both physiologically and morphologically could be compared.

Single unit analyses were based on recordings from 96 TC neurons, 30 TC fibers, and 66 "nonantidromic" units. (Forty-two other "TC units" were also characterized but could not be labeled with confidence as either axonal or somatic.) Measures of antidromic response latencies for $\mathrm{TC}$ neurons and fibers are given in Figure 9. The distribution, ranging from 0.3 to $5.5 \mathrm{msec}$, is skewed such that $62.5 \%$ of all TC neurons had antidromic latencies between 0.4 and $1.1 \mathrm{msec}$. Only $8 \%$ of TC neurons had antidromic latencies greater than 2.0 msec, the remaining $29.5 \%$ falling in the range of 1.2 to $1.9 \mathrm{msec}$. Virtually all TC fiber lalencies lell wilhirn the range or 0.3 to $1.0 \mathrm{msec}$.

It is not clear on the basis of antidromic conduction latencies alone whether there is one or more than one group of TC neurons. It could be argued, for example, that those units the antidromic latencics of which fell within the range of 0.3 to $1.1 \mathrm{msec}$ constitute a separate class, making up the largest fraction of VB units. The large aggregation of TC-fiber latencies in this same range could be taken as evidence to support this idea. Alternatively, the distribution may simply reflect electrode sampling bias. In any case, when units were first grouped according to submodality and their antidromic latencies were plotted (see below), all submodalities had nearly congruent latency spectra. This suggests that, at least with respect to submodal classes, our recordings were not biased. It is true that the "uncertain" submodalities were somewhat underrepresented, but it is not clear that these units were missed because they are smaller or less numerous in VB or because they are found preferentially in nuclei adjoining VB or in parts of VB that were not explored.
A comparison of antidromic (cortical stimulation) and orthodromic (lemniscal or peripheral stimulation) latencies for VB neurons shows a strong, linear, positive correlation $(r=0.85 ; \rho<0.001)$. Thus, VB neurons with short antidromic latencies were activated by short latency medial lemniscal afferents and VB neurons with longer antidromic latencies were activated by longer latency medial lemnis. cal afferents (Fig. 10)

\section{Submodality}

Since we had evidence that antidromic (cortical) and orthodromic (lemniscal) latencies are highly correlated $(r=0.85$ ) for VB units, we then analyzed submodal distributions as a function of antidromic latencies from the cortex. For a total of 107 VB units, $75 \%$ (80 of 107 ) were classified as "cutaneous," $9 \%$ (10 of 107) were classified as "deep," and 16\% (17 of 107) were classified as "uncertain" (including the HT units)

The rather small number of units classified as deep and uncertain precludes any detailed analysis of these two groups. Figure 11 shows the distribution of deep and uncertain units plotted against their antidromic latencies from stimulation of SI cortex. The deep units had a range of latencies from 0.5 to $1.8 \mathrm{msec}$, and the uncertain units had a similar range, 0.3 to $1.7 \mathrm{msec}$. We found no evidence to suggest that differences between these groups were statistically significant.

Figure 11 also shows the distribution of all "cutaneous" units plotted as a function of their antidromic latencies from stimulation of SI cortex. Two-thirds of the cutaneous units fell within the range of 0.4 to $0.9 \mathrm{msec}$, and almost all of the remaining cutaneous units 

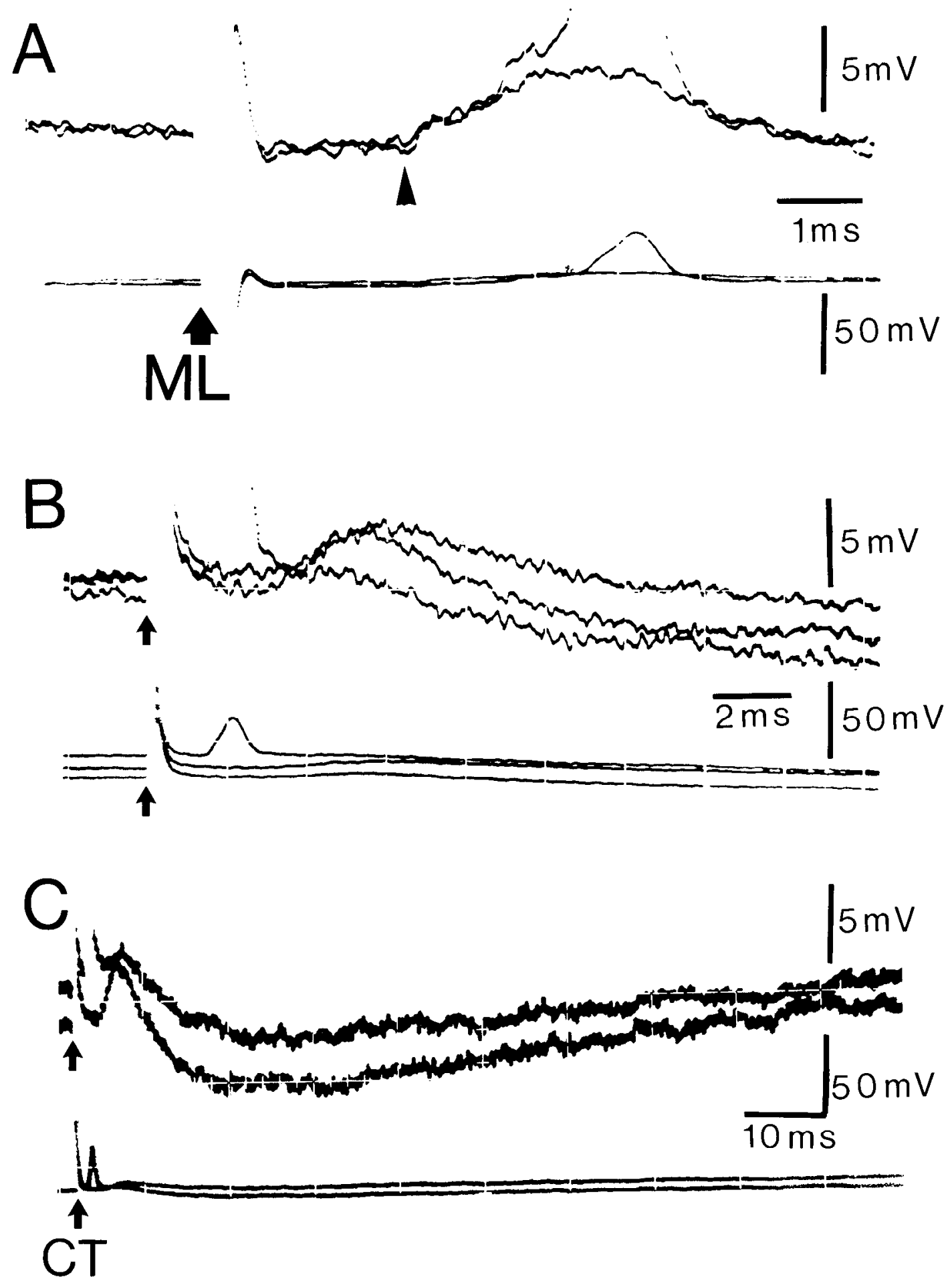

Figure 13. Paired records $(A$ to $C$ ) are high-gain $A C$ recordings (upper traces) and low-gain DC recordings (lower traces). $A$, Intracellular recording of a thalamocortical relay neuron responding with an EPSP and a spike to electrical stimulation of the medial lemniscus (ML). Two superimposed traces. $B$ and $C$. Intracellular recordings of a thalamocortical relay neuron showing its three phases of response to electrical stimulation of the ipsilateral SI cortex (CT). The stimulus artifact is succeeded in order by an antidromic spike, a short latency FPSP, and a long-latency, long-duration IPSP. Three superimposed traces are shown in $B$, two in $C$.

had latencies between 1.0 and 2.0 msec; only two cutaneous units had antidromic latencies longer than $2.0 \mathrm{msec}$.

When the "cutaneous" class was broken down into its constituent subclasses-Hs, Ht, Ps, Pt, and brush-and each was plotted individually as a function of antidromic latency, the distributions were surprisingly uniform. For example, in Figure 12 are shown two distributions for hair units: the upper histograms show the distribution of $\mathrm{Hs}$ units and $\mathrm{Ht}$ units. Both distributions resemble the entire population of cutaneous units in that most hair units (whether transient or sustained) had antidromic latencies in the range of 0.4 to $1.1 \mathrm{msec}$. Only one hair unit had an antidromic latency longer than $1.8 \mathrm{msec}$, and it was an $\mathrm{Ht}$ unit.

The lower histograms in Figure 12 show a similar breakdown for "pressure" (sustained and transient) units. Even with only 27 measurements, it is apparent that the ranges and overall shapes of the two distributions are quite similar.

The five units classified as "brush" are not illustrated, but these had latencies which ranged from 0.6 to $1.6 \mathrm{msec}$. 

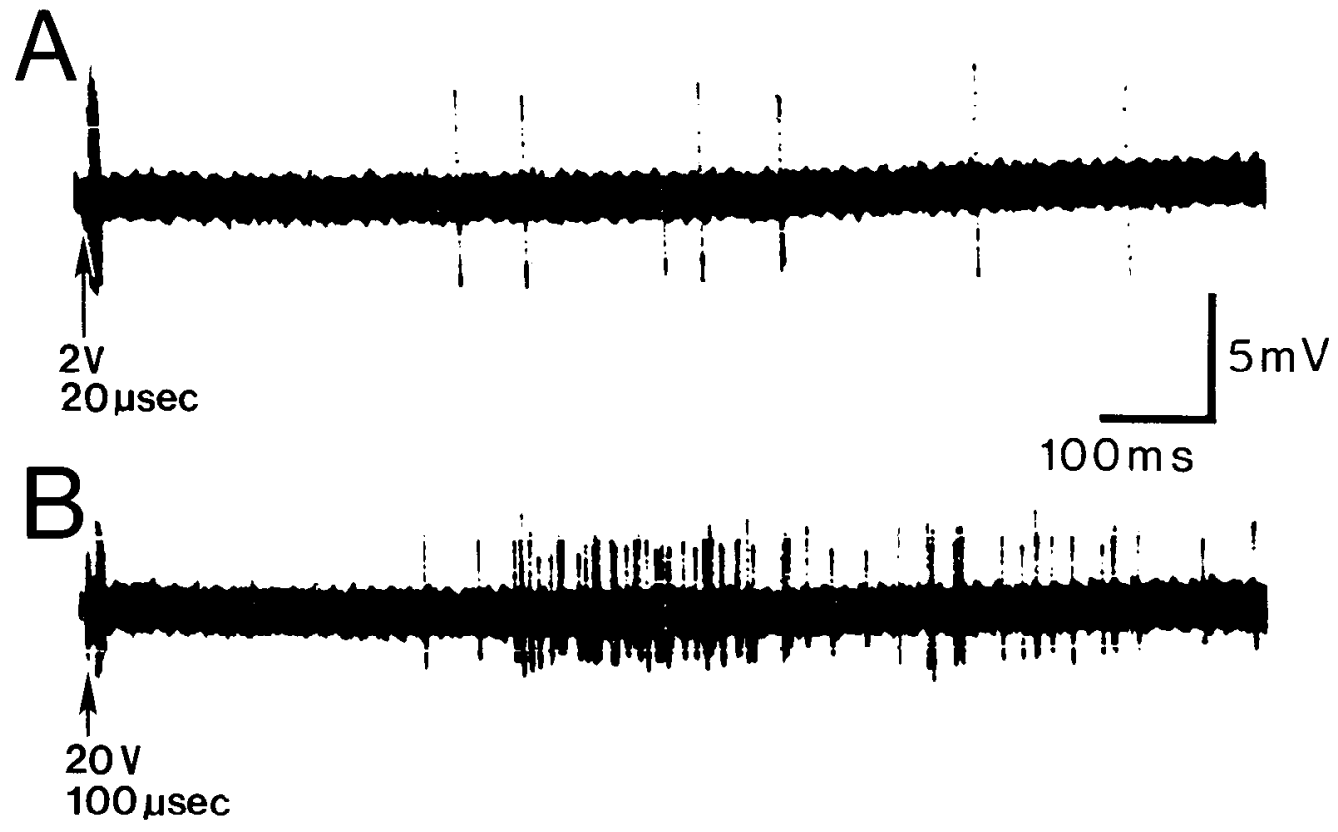

Figure 14. $A$ and $B$. Extracellular recordings from the high-threshold (HT) thalamocortical neuron illustrated in Figure 18 during stimulation of the contralateral median nerve $(M N)$. A short latency excitation is followed by a lengthy inhibition, which is succeeded in turn by a late excitation. $C$ and $D$, Intracellular recording after penetrating the highthreshold neuron, the extracellular responses of which are shown in $A$ and $B$. The upper record is high-gain $A C$; the lower record is low-gain DC.

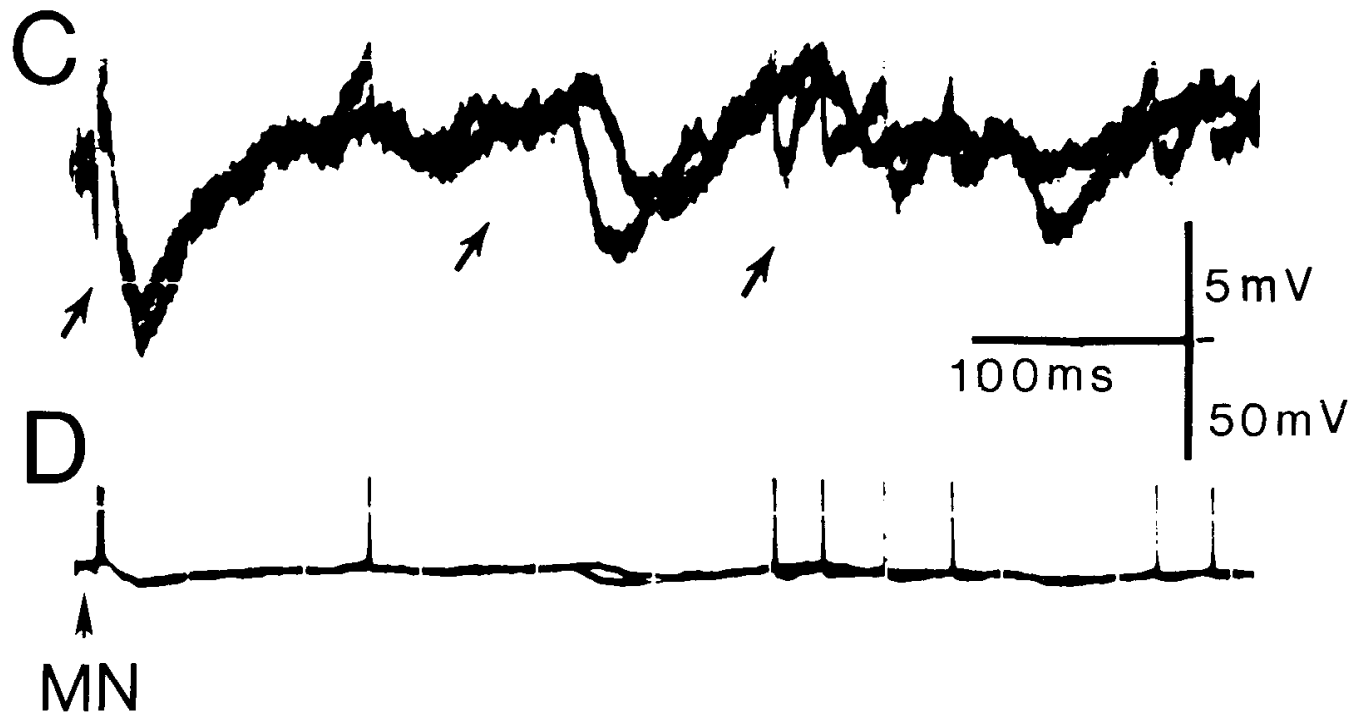
There appears to be an early and an intermediate EPSP-IPSP sequence and a series of late EPSPS (arrows). These three effects may result from inputs carried in peripheral nerve fibers of different diameters.

In general, then, based upon correlated physiological measures, there appears to be little difference in the overall shape of the distribution of individual submodal classes when plotted as a function of cortical antidromic latency. Even the "deep" plus "uncertain" distribution is very similar to the "cutaneous" distribution (compare upper and lower histograms in Fig. 11).

One final comparison made was between "transient" and "sustained" (hair and pressure units) cutaneous subgroups, since these measures have been used to differentiate physiological classes in the visual system (Cleland et al., 1971; Cleland and Levick, 1974; Fukuda and Stone, 1974; Stone and Гukuda, 1974). However, even when plotted in this way, the distributions are nearly congruent, except that the two longest latency units (greater than $2.0 \mathrm{msec}$ ) happened to be transient. Still, based on the number of observations made, our initial impression of these physiological measures and comparisons suggest that there is a very close relationship between the distribution of antidromic (cortical) latencies for all submodal groups (combined) and the distribution of antidromic latencies for any one submodal class. The implication is that each submodal class has a similar distribution of antidromic latencies.

\section{Nonantidromic units}

In addition to those VB units which were classified according to submodality and for which we measured antidromic latencies, an- other group of VB units was also characterized according to submodality but could not be activated antidromically from stimulation of SI cortex; these are our "nonantidromic" units. Of a total of 41 such units, 25 were classified as cutaneous $(11 \mathrm{Hs}, 8 \mathrm{Ht}, 3 \mathrm{Ps}, 1$ Pt, 1 brush), 3 were classified as deep, and 14 were classified as uncertain.

There may be a number of reasons why these units were not driven antidromically from the cortex. One obvious possibility is that the units represent a population of interneurons that does not project to the cortex. A second possibility is that such units might project to cortex but to areas distant from the stimulating site (although usually this possibility was tested) or to another cortical area such as SII. Either or both of the explanations may be appropriate. Whatever the explanation, given the percentages of cutaneous $(59 \%)$, deep $(7 \%)$, and uncertain $(34 \%)$ modalities, our nonantidromic units approximated fairly closely the percentages of these same submodalities for TC units; this suggests that nonantidromic units are not the recipients of any one particular submodal class of afferent.

The lack of a difference based on antidromic latencies between different submodal classes, particularly for TC units, raises the question of the significance of the two morphological classes of VB projection neurons (types I and II) found in the backfilling experi- 


\section{LATERAL}

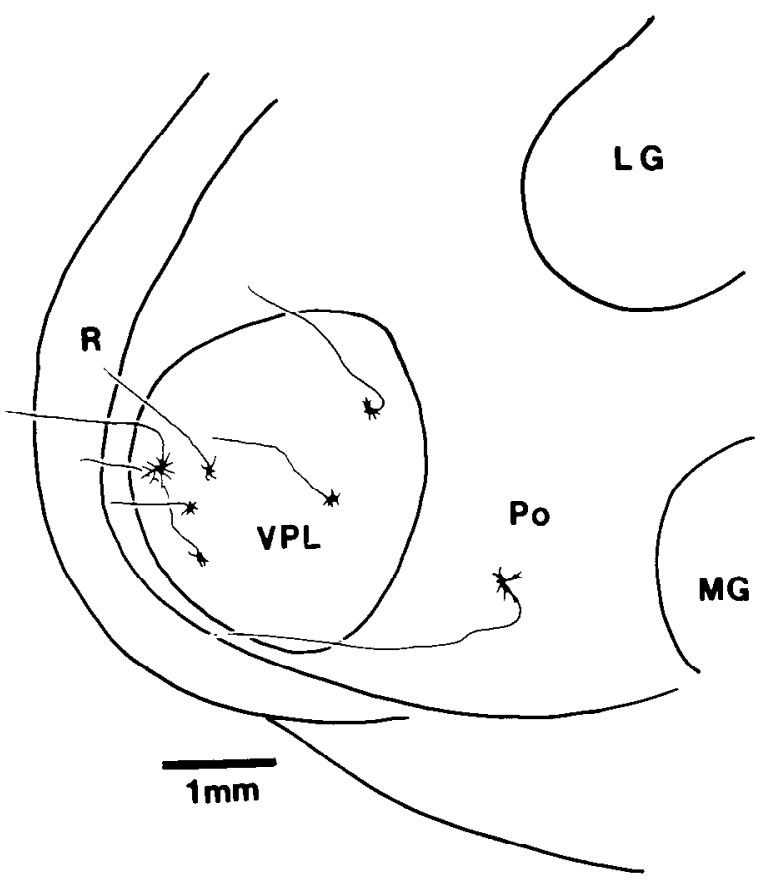

MEDIAL

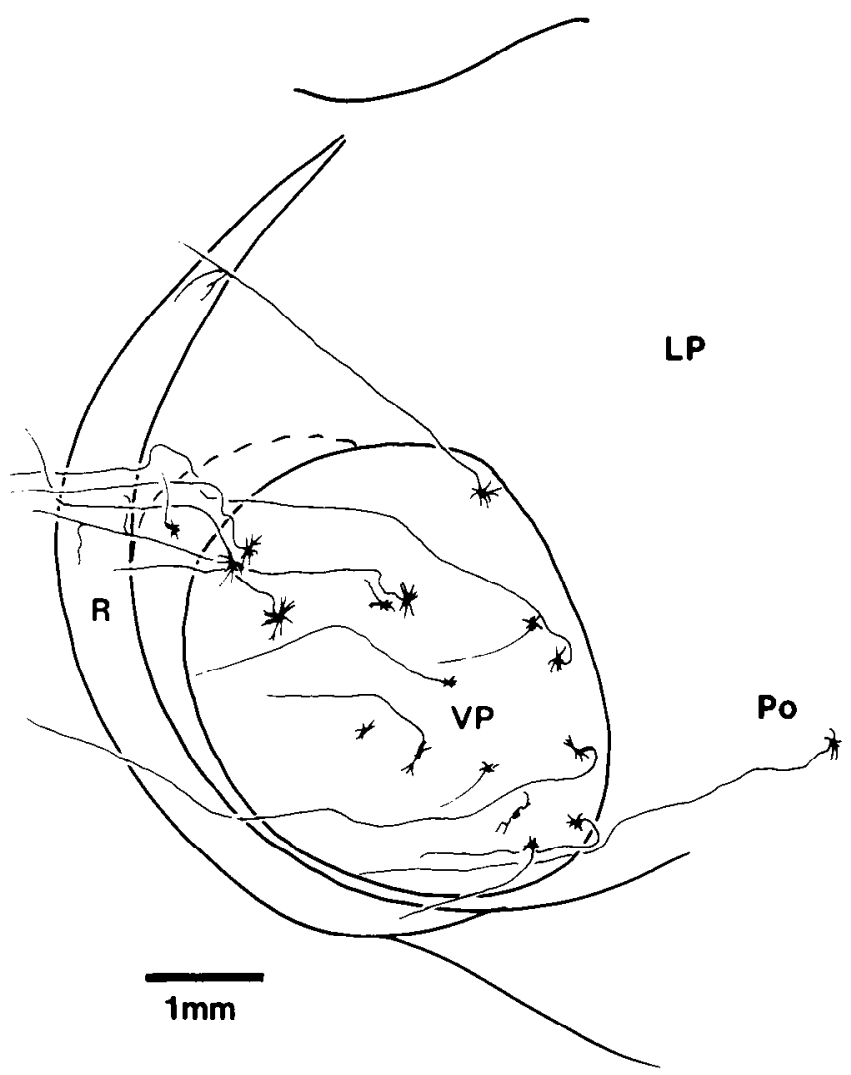

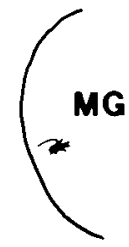

Figure 15. Combined camera lucida plots of sagittal sections at medial and lateral levels through VB, showing the distribution of 26 of the cells injected intracellularly. The dashed line on the medial plot indicates the anterior border of VB at intermediate levels. Six injected cells not shown in VB overlapped those shown on the left of the figure.

TABLE I

Summary of fully characterized cells and axons

Ranges and means of somal size, axon diameter, and antidromic and medial lemniscal latencies for the VB cells that were injected sufficiently well to show detailed morphology. Also included are three thalamocortical axons (T-C) for which the parent cell was not recovered. Receptive fields were all on upper limb distal to elbow or on face

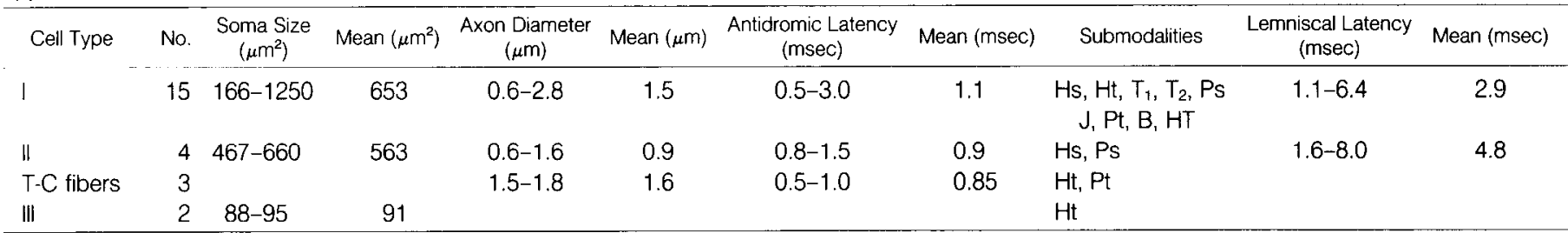

ments. In the last set of experiments to be described, HRP was injected intracellularly into VB neurons which had been classified physiologically. This method provides a direct approach to answering the question just raised.

\section{Intracellular recording and staining}

Thirty-three units were injected intracellularly. Sample records of units that were subsequently injected intracellularly are illustrated in Figures 13 and 14. Of the injected units, 28 were in VB, one was in the posterior complex, 3 were in the magnocellular nucleus of the medial geniculate complex, and 1 was in the ventral nucleus of the medial geniculate complex (Fig. 15). The cell in the posterior complex and one cell in the magnocellular nucleus had somatosensory receptive fields. Three TC fibers for which no cell body could be identified were included among the units stained in VB. These, too, had somatosensory receptive fields (Table I). Antidromic spikes from stimulation of the SI cortex were obtained for 18 of the 28 injected units in VB. These 18, plus 4 other injected VB cells for which no antidromic spike was obtained, were found on histological analysis to possess axons that ran rostrally and entered the internal capsule. Thus, 22 of the injected VB cells will be regarded as TC neurons. Two VB units for which no antidromic spike was obtained were found on subsequent histological analysis to lack stained axons and to resemble thalamic interneurons. The remaining 4 injected units in VB were discarded as too faintly stained for adequate histological analysis.

TC neurons. The areas of the somata of the injected cells ranged from 88 to $1250 \mu \mathrm{m}^{2}$ (mean, $408 \mu \mathrm{m}^{2}$ ). Assuming a conduction distance of $15 \mathrm{~mm}$ and dividing this by the antidromic latency measured for 18 of the cells with somal areas of 155 to $987 \mu \mathrm{m}^{2}$ gives a range of conduction velocities from 5 to $33 \mathrm{~m} / \mathrm{sec}$ (see Table I). Axon diameters of the 22 cells ranged from 0.6 to $2.8 \mu \mathrm{m}$ when measured just beyond the end of the initial segment. For the 18 cells for which antidromic latencies were measured, there was a positive correlation between axon diameter and measured conduction velocity $(r=0.54 ; p<0.05)$. In general, soma size also correlated with axon diameter $(r=0.69 ; \rho<0.01)$. 

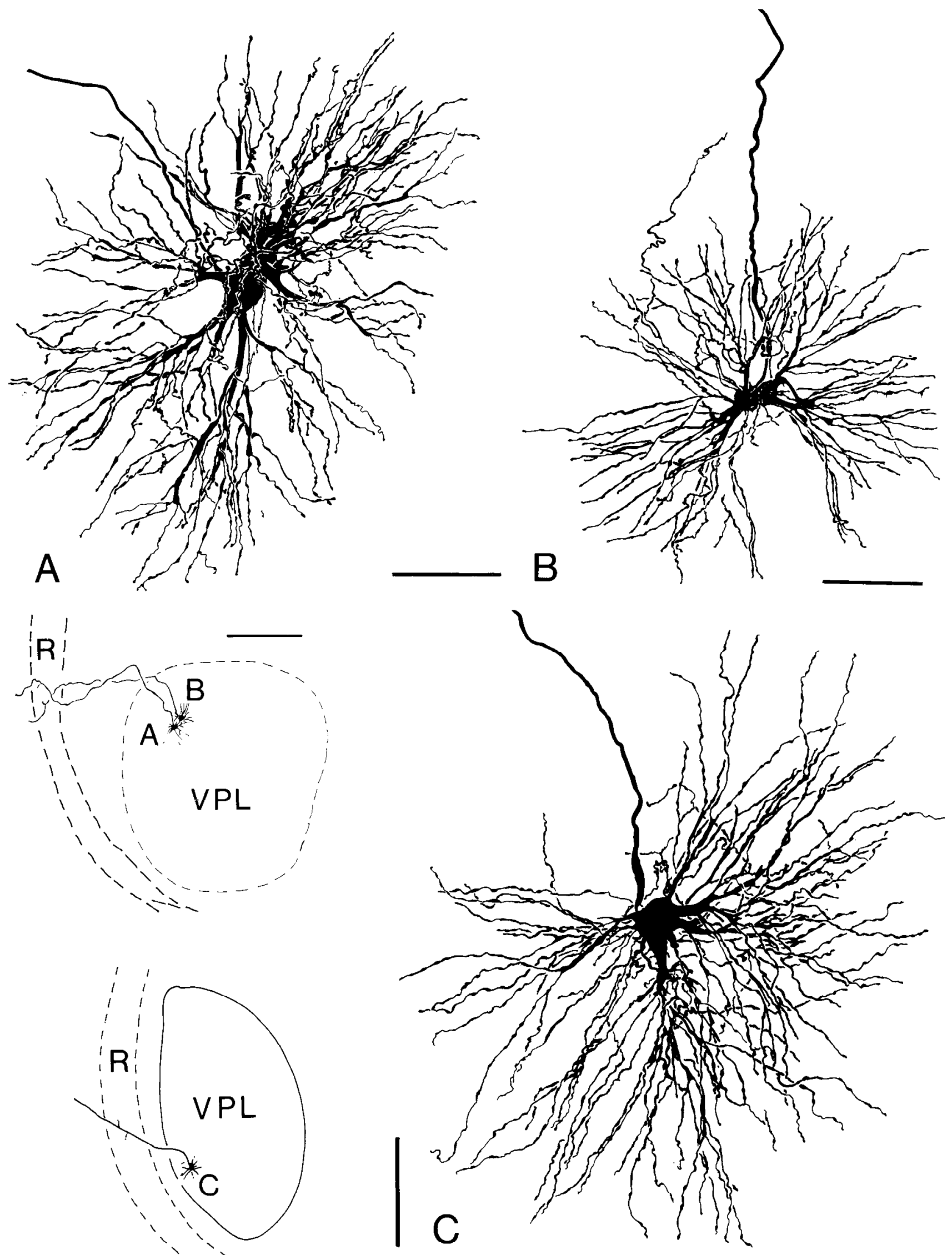

Figure 16. Camera lucida drawings of injected cells identified as type I. Note stout proximal dendrites ending in tufts of secondary branches and lacking dendritic appendages. The axon is stout and gives collaterals only to the reticular nucleus as it passes through to the internal capsule. Bars, $100 \mu \mathrm{m}$ (1 $\mathrm{mm})$. 
Figure 17. Camera lucida drawing of an injected cell identified as type II. Note slender, dichotomously branching dendrites with fine hair-like appendages. The axon is thin and gave off collaterals in reticular nucleus only. Bars, $100 \mu \mathrm{m}(1 \mathrm{~mm})$.
Conduction velocities of medial lemniscal and peripheral inputs to the injected cells, as obtained by measuring the latency to the first spike obtained in response to lemniscal and peripheral stimulation, could also be correlated with soma size and thalamocortical conduction velocity (Table I).

Nineteen of the VB cells with rostrally projecting axons were well stained with HRP, and detailed dendritic morphology was revealed. All cells were multipolar in form with equally radiating dendrites and, in general, could be classified as type I or type $\|$ along lines similar to the larger sample of retrogradely labeled cells (Figs, 16 to 20). Fifteen cells had stout proximal dendrites ending in tufts of branches with some dilatations but no appendages and were, thus, identified as type I cells. Four had slender proximal dendrites that branched more dichotomously and possessed a moderate number of thin, hair-like appendages rather finer than typical dendritic spines and without terminal dilatations. These cells were classified as type II cells.
The injected type I cells had somal areas ranging from 166 to $1250 \mu \mathrm{m}^{2}$. The extent of the dendritic field was directly related to somal size and ranged from 165 to $465 \mu \mathrm{m}$ (mean, $314 \mu \mathrm{m}$ ). The axons of these cells, measured just beyond the end of the initial segment, ranged from 0.6 to $2.8 \mu \mathrm{m}$ (mean, $1.5 \mu \mathrm{m}$ ). Antidromic latencies ranged from 0.5 to $3 \mathrm{msec}$ (mean, $1.1 \mathrm{msec}$ ). The three smallest type I neurons could not be antidromically activated from the cortex but had rostrally running axons with a mean diameter of $0.8 \mu \mathrm{m}$. The axons of all injected type I cells could be traced into the internal capsule though some became very faintly stained at this point. Four of the axons, all of which were well stained, gave off one or two extremely thin $(\sim 0.5 \mu \mathrm{m})$ collaterals as they passed through the reticular nucleus (Fig. 21). None of the collaterais could be traced for any distance, but a few were seen to have dilatations resembling boutons en passant (Fig. 22). No axons of type I cells had collaterals anywhere else in the thalamus, including in VB. 


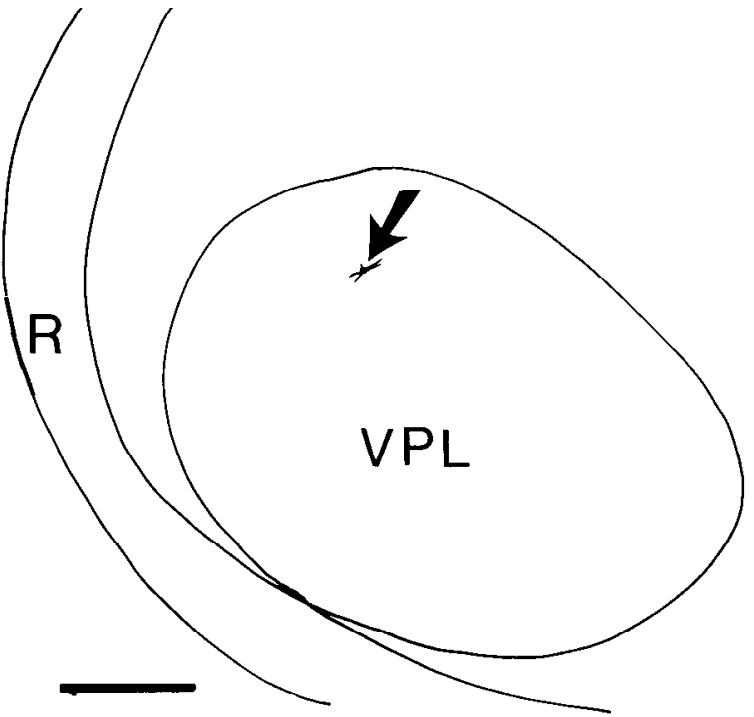

Figure 18. Camera lucida drawing of an injected high-threshold neuron, identified as type I because, although small, it has tufted dendrites. Bar, $100 \mu \mathrm{m}$.

The 4 injected type $\|$ cells had somal areas ranging from 467 to $660 \mu \mathrm{m}^{2}$ with dendritic field extents of 235 to $447 \mu \mathrm{m}$ (mean, 355 $\mu \mathrm{m}$ ). The mean axon diameter was $0.9 \mu \mathrm{m}$ and, for the two cells for which antidromic latencies were obtained, these were 0.8 and 1.5 msec. The axons had no collaterals in VB. One was seen to give off two fine collaterals in the reticular nucleus (Fig. 21).

Receptive fields of TC neurons. Of the 15 type I neurons, there were $5 \mathrm{Ht}, 1 \mathrm{Hs}, 1 \mathrm{~T}, 1 \mathrm{~J}, 3 \mathrm{~T}_{2}, 2$ brush, and $2 \mathrm{HT}$. All except the single $\mathrm{Hs}$ cell responded in a transient manner, and all receptive fields were on the upper limb. The HT neurons (Fig. 18) were the smallest type I cells.

Of the 4 type II neurons, one had a well-defined receptive field on the second and third digits of the hand and gave a sustained response to hair movement. A second had a well-defined receptive field on the innerside of the upper arm and gave a sustained response to skin indentation. The receptive fields of the other two type II neurons could not be satisfactorily determined, but the cells responded in a sustained fashion to coarse manipulations of the upper limb.

Interneurons. Two small VB neurons for which no antidromic spike could be obtained were injected (Figs. 23 and 24). One had a receptive field on the back of the hand and was classified as Ht. No receptive field could be obtained for the second. Somal areas were 88 and $95 \mu \mathrm{m}^{2}$. Each had 4 or 5 slender $(0.5$ to $1 \mu \mathrm{m})$ primary dendrites which branched little, if at all, and which twisted and curved over 50 to $100 \mu \mathrm{m}$. Each dendrite showed numerous dilatations, some as large as $5 \mu \mathrm{m}$ in diameter, others much less than that. No obvious axon could be identified on either cells

\section{Discussion}

In the present study, we set out to establish functional relationships between morphological and physiological classes of VB neurons using separate and combined anatomical and physiological approaches. Our results suggest that, while a variety of physiological submodalities can be distinguished in the inputs to VB cells, the nucleus is composed of only three morphological cell classes: two populations of projection neuron (types I and II) and one population of interneuron (type III), no one of which can be associated exclusively with a single submodality. In terms of functional organization, therefore, the customary classification of submodalities is not represented by morphologically distinct classes of neurons. One class of neuron (type I neurons) appears to be represented across most, if not all, submodalities. Thus, with respect to the functional significance of different morphological classes, morphological type may be correlated with something other than the conventional submodal classes.

Single-unit and extracellular HRP studies. Before discussing the results from the intracellular filling experiments, it is useful to review the results based on the separate anatomical and physiological experiments. Though providing less direct functional measures, these nevertheless provide a good background against which the more direct intracellular data may be compared.

Experiments in which HRP was injected into the internal capsule adjacent to VB revealed two populations of projection neuron which we have termed type I and type II neurons. Both type I and type I| neurons are multipolar in shape with radially arranged dendrites, and both resemble the classical Buschzell first described by Kölliker (1896). Type I neurons can be distinguished from type II neurons by 


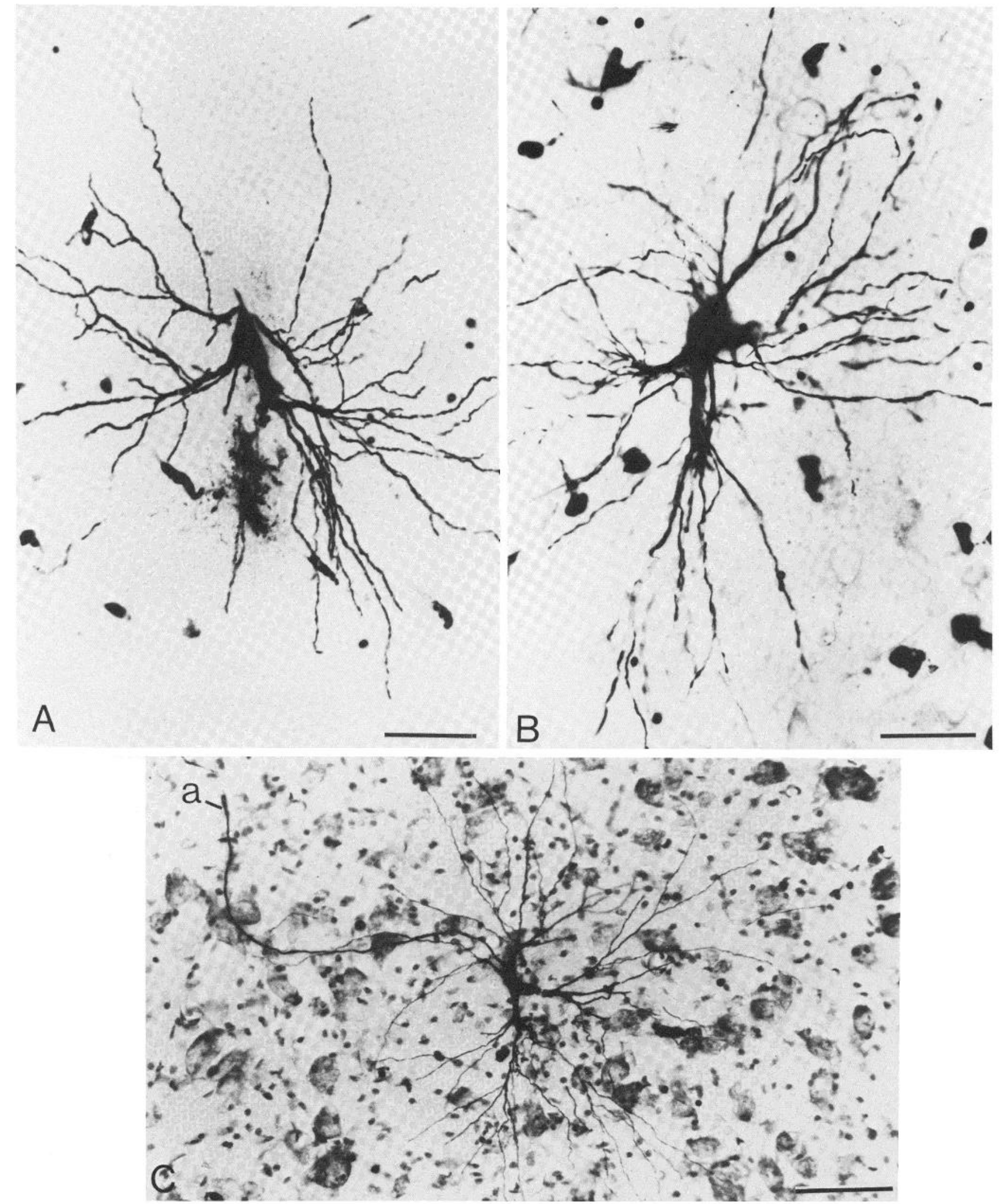

Figure 19. Photomicrographs of injected type I $(A$ and $B)$ and type $\|(C)$ cells. The section containing $C$ has been counterstained with thionin. $a$, axon. Bars, $50 \mu \mathrm{m}$. 

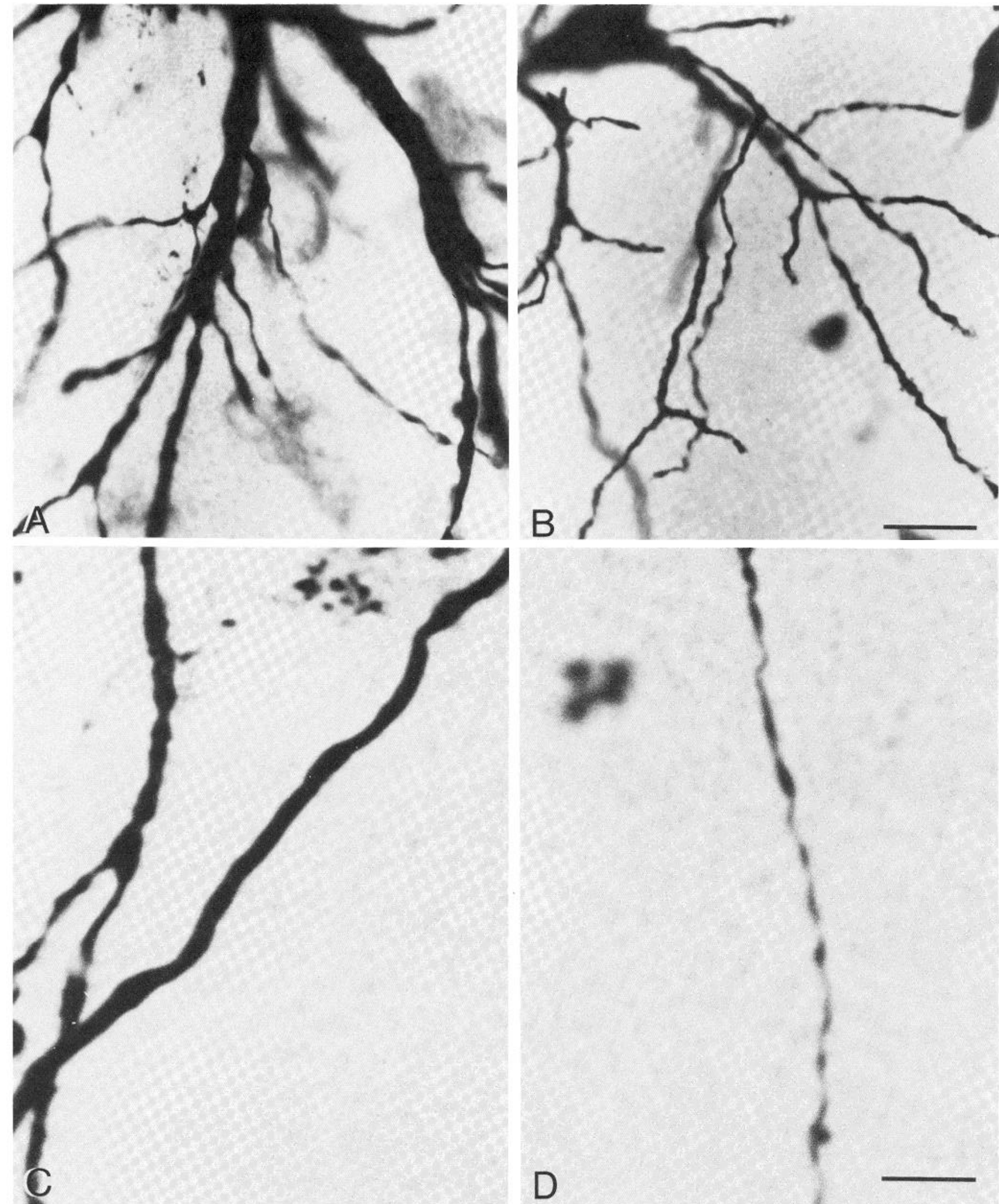

)
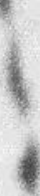

Figure 20. Photomicrographs at the same magnification showing dendrites and axon of injected type I cell $(A$ and $C)$ and type $\|$ cells $(B$ and $D)$. Bars, $25 \mu \mathrm{m}$.

their larger average somal areas, larger caliber axons, larger average dendritic field diameters, and distinctive smooth, tufted dendrites as opposed to the thinner, less tufted, and sometimes hair-covered dendrites of type II cells.
Type I VB neurons are quite likely the same as the large, multipolar neurons described in VB of the cat in Golgi studies (Rainey and Jones, 1983) and are quite similar to type I neurons in the medial and lateral geniculate nuclei of the cat (Morest, 1965; Guillery, 1966). 


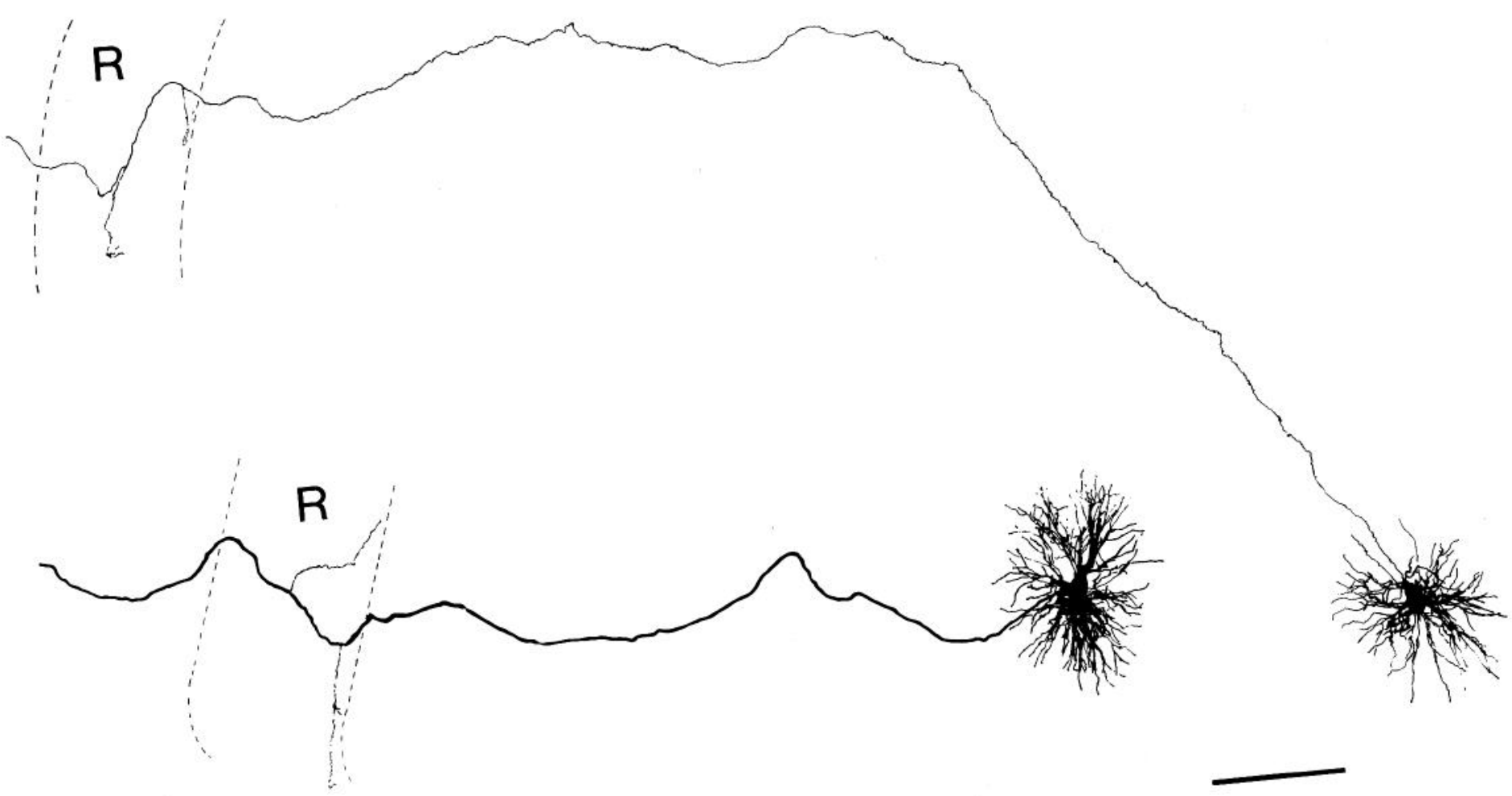

Figure 21. Camera lucida drawings of injected type I (lower) and type II (upper) cells the axons of which had stained collaterals in the reticular nucleus. Bar, $250 \mu \mathrm{m}$.

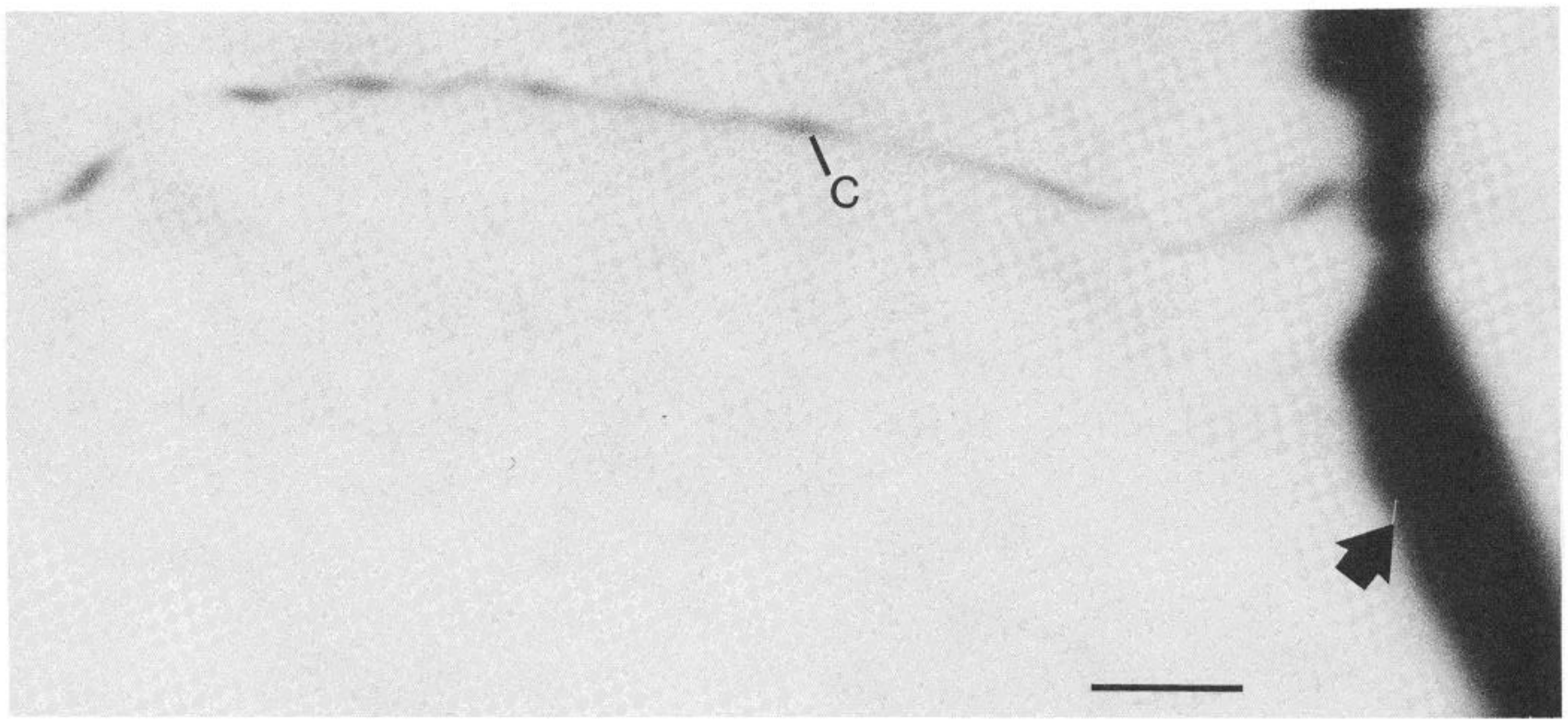

Figure 22. Photomicrograph showing a thin beaded collateral (c) of the large axon of a type I cell (arrow) in the reticular nucleus. Bar, $25 \mu \mathrm{m}$.

They are also similar to type I neurons described in HRP and Golgi material in the Galago VB (Pearson and Haines, 1980), and to cells intracellularly injected by Peschanski et al. (1984) in the rat VB.

Neurons that we classified as type \| are similar to the type ॥ neurons described in Galago by Pearson and Haines (1980), except that many fewer grapelike appendages were seen in our material. In the few instances in which these appendages were visible, they numbered only 4 or 5 at any one branch point and there were never more than 15 to 20 /neuron.

Our measurements of peripheral conduction velocities confirm earlier reports that conduction velocity is related directly to receptive field size, since the sizes of the receptive fields decrease as they move from proximal to distal on a limb (Mountcastle, 1957; Powell and Mountcastle, 1959; Poggio and Mountcastle, 1963; Tsumoto, 1974). Direct comparison of orthodromic (lemniscal) and antidromic (cortical) latencies for individual VB units revealed a strong correlation $(r=0.85)$ indicating that, in general, those units which were activated at short latency by lemniscal stimulation were also activated at short latency by cortical stimulation. This "high-fidelity" transmission has been described by Tsumoto (1974) and is probably part of the basis of what Poggio and Mountcastle (1960) referred to as highly "secure" synapses in the lemniscal pathway.

Distributions of antidromic latencies from cortex, whether for all TC units or for any particular submodal class of TC units, were 


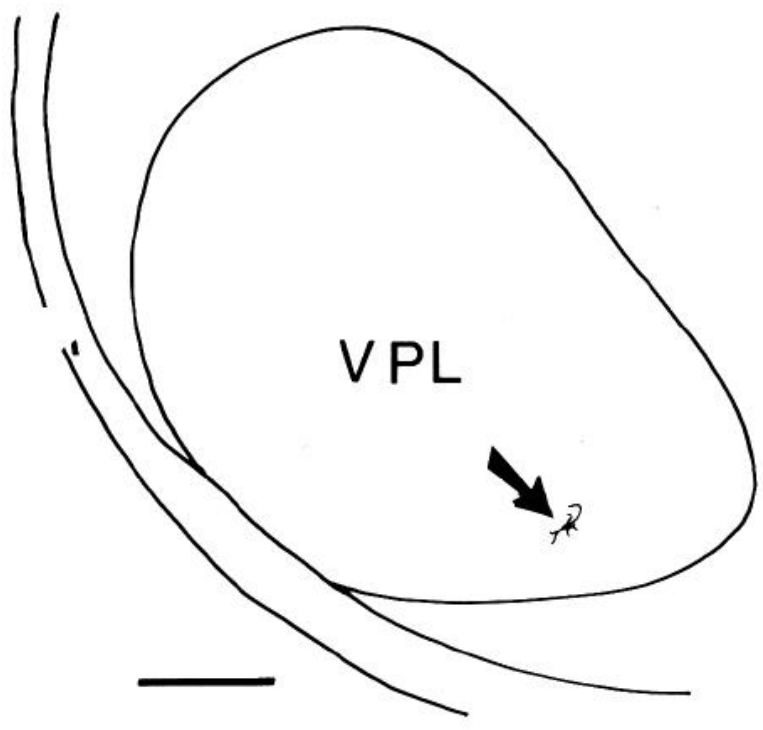


similar: most $(80 \%)$ had short latency responses $(0.3$ to $1.0 \mathrm{mscc})$, whereas only $20 \%$ had latencies longer that $1.0 \mathrm{msec}$ (Fig. 9). These single unit data can provide only an incomplete picture of any submodal/morphological relationships and are based on indirect evidence. However, each submodality had a similar antidromic latency spcctrum and each approximated in range and frequency the overall population spectrum (Fig. 11). Hence, all somesthetic submodalities might be represented across all morphological types. That is, no one portion of the total population spectrum of antidromic latencies could be attributed to a single submodality (or even a group of related submodalities such as "pressure," "hair," or "deep"); the alternative, that each submodality might be represented across all of the morphological cell classes in VB, was considered and supported in part by intracellular recording and injection of HRP.

The history of attempts to relate specific receptor and fiber types in the upper levels of the somatic sensory system to the conventional submodalities is long, but it has been largely unsuccessful. We have also not been successful in correlating cell types in VB with these submodalities. If the type I and type $\|$ relay cells are to be correlated with some physiological property, it will be necessary to examine them in different terms, e.g., in relation to their discharge patterns which, in the intracelluar results to be described below, seem to be either tonic or phasic.

Intracellular experiments. Anatomical classification of injected VB projection neurons supports the type I, type II classification based on retrograde labeling. However, more subtle morphological features of dendritic and axonal arborizations were apparent in the neurons filled intracellularly (Figs. 14 to 22) and average dendritic field diameters were slightly larger for intracellularly labeled neurons. Despite these differences, however, none was sufficient to cause us to alter our classification scheme as originally formulated for retrogradely labeled neurons.

In addition to these two classes of projection neuron, we also recorded from and injected intracellularly two type III neurons which could not be activated antidromically from the SI cortex and for which no clear axon could be found. These features, as well as their complex dendritic arrays and small somata, suggest that these cells are interneurons. The two cells resemble putative interneurons in VB and other thalamic nuclei, as identified in Golgi and immunocytochemical studies (Tömböl, 1967; Szentágothai, 1973; Morest, 1975; Spreafico et al., 1983; Penny et al., 1983).

Submodality. Fifteen injected neurons with type I morphology were recovered histologically, and these show clearly that type I neurons are not associatcd with any single submodality. For example, of the 15, 6 were classified as "hair" $(5 \mathrm{Ht}, 1 \mathrm{Hs}), 4$ were classified as "tap" (1 T1, 3 T2), 2 were classified as "brush," 1 was classified as joint, and 2 were classified as high threshold (HT). Fourteen of these units responded phasically and one tonically. Four type $\|$ cells were recovered histologically, but only two of the four could be adequately classified according to submodality. Both had "sustained" responses (1 Hs, $1 \mathrm{Ps}$ ), and this appeared to be true of the other two as well. This result, coupled with the fact that only one of 15 well-stained type I neurons had "sustained" responses, raises the possibility that there may be a relationship between type ॥ morphology and tonic responses and of type I with phasic responses. Perhaps "hairy" dendrites, like the presence of grape-like dendritic appendages on some lateral geniculate relay neurons, may be correlated with sustained responses (Friedlander et al., 1981). Our conclusion is based on rather few observations, so it must remain tentative. Moreover, our single unit data comparing antidromic latencies of "sustained" versus "transient" units did not reveal different spectra, either one from the other or from the total VB antidromic latency spectrum. Only two type III neurons were recovered histologically, and only one had a receptive field that we could classify definitively $(\mathrm{Ht})$. By itself this single observation offers little insight into the question of which classes of submodal afferents may terminate on interneurons. However, if we tentatively assume that most of the "nonantidromic" units examined throughout all phases of this study are interneurons, then our single unit data suggest that most submodal types (hair, pressure, brush, joint, tap, and high threshold) are represented across these cells also.

In summary, classes of submodal afferents which drive type I neurons are quite heterogeneous, suggesting that no one conventional submodality is the source of input to this morphological class. While the data are much less certain for type II and type III neurons, some evidence for a similar heterogeneity of submodal representation is apparent.

One of the issues raised in the results is that of electrode sampling bias and how it may affect our interpretation of the relationship(s) between submodal and morphological classes. Our intracellularly stained sample contains more type I than type II neurons and more type II than type III neurons and, since these represent a decreasing series in terms of soma size, our sample may be biased toward the larger VB neurons. However, even in light of this, there is no evidence with respect to submodality that our sample was biased, and this point should be emphasized. If one morphological class, say type! neurons, was found to represent a single submodality, then we could not be sure either that type I neurons represent only that single submodal class or that our recordings were not biased toward one particular submodal or morphological class. Because virtually all submodal classes were represented across type I neurons, the possitbility of a 1:1 relationship between morphological class and any submodal class, at least for type I cells, is eliminated. The case for type II and III cells is much less certain. However, of the two type II neurons which we were able to classify according to submodality, both had "sustained" responses, and only one of the 15 type I neurons had sustained responses. Hence, type II neurons may be correlated with sustained responses and type I neurons may be correlated with transient responses. A similar hypothesis based on anatomical studies alone has been proposed by Pearson and Haines (1980) in the Galago. It is noteworthy that in the visual system, one principal functional classification emphasizes the differences between neurons with (brisk) sustained ( $X$ cells) and (brisk) transient responses ( $Y$ cells) (Cleland and Levick, 1974; Stone and Fukuda, 1974) and to a large extent can be correlated with morphological classes in the dorsal lateral geniculate nucleus (Friedlander et al., 1981).

Within the central "core" and surrounding "shell" regions of the monkey VB, in which neurons tend to be aggregated into clusters, a given cluster contains neurons with the same place and submodal specificity (Poggio and Mountcastle, 1960, 1963). Anterograde labeling from the dorsal column nuclei or retrograde labeling from $\mathrm{SI}$ cortex in cats and monkeys (Hand and Van Winkle, 1976; Kosar and Hand, 1981; Jones et al., 1979, 1982) also reveal that the principal unit of VB organization is a slender cluster of neurons which, in monkeys at least, takes the form of a slender cylindrical rod composed of neurons running largely in a rostrocaudal direction (although conforming to the overall curve of the lamellae in VB), and these, too, are place and modality specific (Jones and Friedman, 1982; Jones et al., 1982). In cats, the place- and modality-specific unit is more likely to be a short cluster rather than a long rod of neurons (Kosar and Hand, 1981).

One question raised by the present study is whether a functional and morphological cluster or rod in VB contains one, two, or three morphological classes of cell. In Nissl-stained material, individual clusters of VB neurons contain large, medium, and small cells. In retrograde transport experiments in which HRP is injected into a small region of SI cortex, rods or clusters of labeled VB neurons include large (presumably type I) and medium-sized (presumably type II) neurons (Jones et al., 1982). This, coupled with the fact that neurons immunoreactive for glutamic acid decarboxylase (GAD) in VB (all of which have small somata and account for approximately $30 \%$ of the total neuron population in the cat) are located throughout the nucleus (Penny et al., 1983), suggests that every VB rod or cluster may contain all three morphological classes. Hence, all three morphological classes would participate in the processing of inputs 
related to all of the conventional submodalities, although individual VB rods would still be submodality specific. This clustered or rodlike and submodal-specific organization may be "impressed" upon the VB complex by a similar submodal specific organization of the dorsal column nuclei (Dykes et al., 1982), and it is maintained by the projection of each VB rod or cluster to a single functional column in SI (Jones et al., 1982).

In the visual system, which is not customarily divided into submodalities comparable to those in the somatosensory system, different anatomical classes of cells are often segregated in the lateral geniculate body. Yet all types lie along the same projection column and contribute to the innervation of a single column of cortex whereas in the somesthetic modality, which is divisible into submodalities, different anatomical classes are not segregated in VB, and all contribute to the innervation of a single submodal-specific column of cortex. It is conceivable, therefore, that the traditional submodality classifications in the somatosensory system are inappropriate at this level of resolution and that some defining factor comparable to that leading to the $X$ and $Y$ distinction in the visual system may be more uscful.

Collateral projections. The significance of collateral projections to the thalamic reticular nucleus relates first to the fact that all thalamic nuclei including VB are interconnecrted with the thalamic reticular nucleus (Jones, 1975), thus establishing a reciprocity of connections vetween VB and the reticular nucleus; second, virtually every neuron in the thalamic reticular nucleus is GAD-immunoreactive, suggesting that these neurons use GABA as their neurontransmitter and are thus inhibitory in function (Houser et al., 1980; Oertel et al., 1983).

Only 5 of 19 cells labeled intracellularly could be shown to have RTN collaterals. Where RTN collaterals could not be identified, the staining of the axon was becoming light at the RTN. The collaterals arose from both typc I and type II ncurons, suggesting that they are not restricted to the axons of a particular class of VB neuron. Based upon similar intracellular studies of cat lateral geniculate neurons in which $X_{-}, Y_{-}$, and $W$-cells all issue collateral branches to the perigeniculate nucleus (Ahlsén et al., 1978; Friedlander et al., 1981; Stanford et al., 1983), it may be a general rule that all thalamic relay neurons, at least in VB and LGN, project to the reticular nucleus by way of axon collaterals. This, however, has to be confirmed for VB because of the low proportion of collaterals observed in our experiments.

The finding that VB relay neurons give off axon collaterals only in the RTN is important in the context of the traditional idea that recurrent collaterals of VB relay neurons terminate within VB itsclf and that they play a significant role in shaping the responses of $V B$ cells to peripheral stimuli (Andersen et al., 1964). It now seems evident that each dorsal thalamic nucleus has two populations of interneurons related to it, one intrinsic to the nucleus and the other in the sector of the reticular nucleus related to that nucleus. Both groups of interneurons, since they are GAD-positive, are probably inhibitory. However, the lack of intranuclear collaterals on the axons of the thalamocortical relay cells suggests that the intrinsic interneurons are likely to be activated by afferent driving rather than in a recurrent manner. The reticular nucleus (including its visual part in the cat-the perigeniculate nucleus), therefore, is likely to provide recurrent inhibitory effects on the relay nucleus (Dubin and Cleland, 1977; Lindström, 1982). A small number of lateral geniculate projection neurons has been shown to possess intrageniculate axon collaterals (Ahlsén et al., 1978; Friedlander et al., 1981; Stanford et al., 1983). It is unclear whether these are true intranuclear collaterals or collaterals destined to terminate in the perigeniculate nucleus. We observed no similar intranuclear collaterals in our sample. However, since the number of VB axons filled sufficiently well to trace for any distance was quite small, we cannot exclude the possibility that some VB neurons may also have intranuclear collaterals.

\section{References}

Adams, J. C. (1977) Technical considerations in the use of horseradish peroxidase as a neuronal marker. Neuroscience 2: 141-146.

Ahlsén, G., S. Lindström, and E. Sybirska (1978) Subcortical axon collaterals of principal cells in the lateral geniculate body of the cat. Brain Res. 156 : 106-109.

Andersen, P., J. C. Eccles, and T. A. Sears (1964) The ventro-basal complex of the thalamus: types of cells, their responses and their functional organization. J. Physiol. (Lond.) 174: 370-399.

Andersen, P., S. A. Andersson, and S. Landgren (1966) Some properties of the thalamic relay cells in the spino-cervico-lemniscal path. Acta Physiol. Scand. 68: 72-83.

Bishop, P. O., W. Burke, and R. Davis (1962) Single unit recording from antidromically activated optic radiation neurons. J. Physiol. (Lond.) 162: $432-450$

Cleland, B. G., and W. R. Levick (1974) Brisk and sluggish concentrically organized gariglion cells in the cat's retina. J. Physiol. (Lond.) 240: 421456.

Cleland, B. G., M. W. Dubin, and W. R. Levick (1971) Sustained and transient cells in the cat's retina and lateral geniculate nucleus. J. Physiol. (Lond.) 217: 473-496

Darian-Smith, I., G. Phillips, and R. D. Ryan (1963) Functional organization in the trigeminal main sensory and rostral spinal nuclei of the cat. J. Physiol. (Lond.) 168: 129-146.

Dubin, M. W., and B. G. Cleland (1977) Organization of visual inputs to interneurons of lateral geniculate nucleus of the cat. J. Neurophysiol. 40: $410-427$

Dykes, R. W., M. Sur, M. M. Merzenich, J. H. Kaas, and R. J. Nelson (1981) Regional segregation of neurons responding to quickly adapting, slowly adapting, deep, and Pacinian receptors within thalamic ventroposterior lateral and ventroposterior inferior nuclei in the squirrel monkey (Saimiri sciurus). Neuroscience 6: 1687-1692.

Dykes, R. W., D. D. Rasmusson, D. Sretavan, and N. B. Rehman (1982) Submodality segregation and receptive field sequences in cuneate, gracile, and external cuneate nuclei of the cat. J. Neurophysiol. 47: 389-416.

Fisher, G. R., B. Freeman and M. J. Rowe (1983) Organization of parallel projections from pacinian afferent fibers to somatosensory cortical areas I and $I I$ in the cat. J. Neurophysiol. 49: 75-97.

Fricdlander, M. J., C. -S. Lin, L. R. Stanford, and S. M. Sherman (1981) Morphology of functionally identified neurons in the lateral geniculate nucleus of the cat. J. Neurophysiol. 46: 80-129.

Friedman, D. P., and E. G. Jones (1981) Thalamic input to areas $3 a$ and 2 in monkeys. J. Neurophysiol. 45: 59-85.

Fukuda, $Y$., and J. Stone (1974) Retinal distribution and central projections of $Y_{-}, X_{-}$, and $W$-cells of the cat's retina. J. Neurophysiol. 37: 749-772.

Guillery, R. W. (1966) A study of Golgi preparations from the dorsal lateral geniculate nucleus of the adult cat. I. Comp. Neurol. 128: 21-50.

Hand, P. J., and T. Van Winkle (1976) The efferent connections of the feline nucleus cuneatus. J. Comp. Neurol. 171: 83-110.

Honda, C. N., S. Mcnsc, and E. R. Perl (1983) Neurons in ventrobasal region of cat thalamus selectively responsive to noxious mechanical stimulation. J. Neurophysiol. 49: 662-673.

Houser, C. R., J. E. Vaughn, R. P. Barber, and E. Roberts (1980) GABA neurons are the major cell type of the nucleus reticularis thalamus. Brain Res. 200: 341-354.

Jones, E. G. (1975) Some aspects of the organization of the thalamic reticular complex. J. Comp. Neurol. 162: 285-308.

Jones, E. G., and D. P. Friedman (1982) Projection pattern of functional components of thalamic ventrobasal complex on monkey somatosensory cortex. J. Neurophysiol. 48: 521-544.

Joncs, E. G., S. P. Wise, and J. D. Coulter (1979) Differential thalamic relationships of sensory-motor and parietal cortical fields in monkeys. J. Comp. Neurol. 183: 833-882.

Jones, E. G., D. P. Friedman, and S. H. C. Hendry (1982) Thalamic basis of place- and modality-specific columns in monkey somatosensory cortex: a correlative anatomical and physiological study. J. Neurophysiol. 48: 545568.

Kniffki, K. -D., and K. Mizumura (1983) Responses of neurons in VPL and VPL-VL region of the cat to algesic stimulation of muscle and tendon. $J$. Neurophysiol. 49: 649-661.

Kölliker, A. (von) (1896) Handbuch der Gewebelehre des Menschen Ed. 6, Vol. 2: Nervensystem des Menschen und der Thiere, W. Englemann, Leipzig.

Kosar, E., and P. J. Hand (1981) First somatosensory cortical columns and 
associated neuronal clusters of nucleus ventralis posterolatralis of the cat: an anatomical demonstration. J. Comp. Neurol. 198: 515-539.

Lindström, S. (1982) Synaptic organization of inhibitory pathways to principal cells in the lateral geniculate nucleus of the cat. Brain Res. 234: 447-453.

Morest, D. K. (1965) The lateral tegmental system of the midbrain and the medial geniculate body: A study with Nauta and Golgi methods in cat. J. Anat. (Lond.) 99: 611-634.

Morest, D. K. (1975) Synaptic relationships of Golgi type II cells in the medial geniculate body of the cat. J. Comp. Neurol. 162: 157-194.

Mountcastle, V. B. (1957) Modality and topographic properties of single neurons of cat's somatic sensory cortex. J. Neurophysiol. 20:408-437.

Oertel, W. H., A. M. Graybiel, E. Mugnaini, R. P. Elde, D. E. Schmechel, and I. J. Kopin (1983) Coexistence of glutamic acid decarboxylase- and somatostatin-like immunoreactivity in neurons of the feline rucleus reticularis thalami. J. Neurosci. 3: 1322-1332.

Pearson, J. C., and D. E. Haines (1980) Somatosensory thalamus of a prosimian primate (Galago senegalensis). II. An HRP and Golgi study of the ventral posterolateral nucleus (VPL). J. Comp. Neurol. 190: 559-580.

Penny, G. R., D. Fitzpatrick, D. E. Schmechel, and I. T. Diamond (1983) Glutamic acid decarboxylase-immunoreactive neurons and horseradish peroxidase-labeled projection neurons in the ventral posterior nucleus of the cat and Gaiago senegalensis. J. Neurosci. 3: 1868-1887.

Peschanski, M. C. L. Lee, and H. J. Ralston, III (1984) The structural organization of the ventrobasal complex of the rat as revealed by the analysis of physiologically characterized neurons injected intracellularly with horseradish peroxidase. Brain Res. 297: 63-74.

Poggio, G. F., and V. B. Mountcastle (1960) A study of the functional contributions of the lemniscal and spinothalamic systems to somatic sensibility: central nervous mechanisms in pain. Bull. Johns Hopkins Hosp. 106: 266-216.

Poggio, G. F., and V. B. Mountcastle (1963) The functional properties of ventrobasal thalamic neurons studied in unanesthetized monkeys. J. Neurophysiol. 26: 775-806.

Powell, T. P. S., and V. B. Mountcastle (1959) Some aspects of the functional organization of the cortex of the postcentral gyrus of the monkey: A correlation of findings obtained in a single unit analysis with cytoarchitecture. Bull. Johns Hopkins Hosp. 105: 133-162.

Rainey, W. T., and E. G. Jones (1983) Spatial distribution of individual medial lemniscal axons in the thalamic ventrobasal complex of the cat. Exp. Brain Res. 49: 229-246.

Spreafico, R., D. E. Schmechel, L. C. Ellis, Jr., and A. Rustioni (1983) Cortical relay neurons and interneurons in the nucleus ventralis posterolateralis of cats: A horseradish peroxidase, electron-microscopic, Golgi and immunocytochemical study. Neuroscience 9: 491-510.

Stanford, L. R., M. J. Friedlander, and S. M. Sherman (1983) Morphological and physiological properties of geniculate W-cells of the cat: A comparison with X-and Y-cells. J. Neurophysiol. 50: 582-608.

Stone, J., and Y. Fukuda (1974) Properties of cat retinal ganglion cells. A comparison of W-cells with X-and Y-cells. J. Neurophysiol. 37: 722-748.

Szentágothai, J. (1973) Neuronal and synaptic architecture of the lateral geniculate nucleus, In Handbook of Sensory Physiology, R. Jung, ed., Vol. VIl/3B, pp. 141-176, Springer-Verlag, Berlin.

Tömböl, T. (1967) Short neurons and their synaptic relations in specific thalamic nuelcei. Brain Res. 3: 307-326.

Tsumoto, T. (1974) Characteristics of the thalamic ventrobasal relay neurons as a function of conduction velocities of medial lemniscal fibers. Exp. Brain Ros. 21: 211224

Updyke, B. V. (1979) A Golgi study of the class V cell in the visual thalamus of the cat. J. Comp. Neurol. 186: 603-620.

Wolstencroft, J. H. (1964) Reticulospinal neurons. J. Physiol. (Lond.) 174: 91-108.

Yen, C. - T., and E. G. Jones (1983) Intracellular staining of physiologically identified neurons and axons in the somatosensory thalamus of the cat. Brain Res, 280: 148-154. 